PATRÍCIA MARIA RODRIGUES GONÇALVES

\title{
COMO AS DEMARCAÇÕES NA TELA INFLUENCIAM A MANIFESTAÇÃO DO EFEITO ATENCIONAL AUTOMÁTICO
}


Candidata:

Patrícia Maria Rodrigues Gonçalves

Título da Dissertação: $\quad$ Como as demarcações na tela influenciam a manifestação do efeito atencional automático

A Comissão Julgadora dos trabalhos de Defesa da Dissertação de Mestrado, em sessão pública realizada a ..........................................., considerou a candidata:
( ) Aprovada
( ) Reprovada

Examinador(a): Nome:

Instituição:

Assinatura:

Examinador(a): Nome:

Instituição:

Assinatura:

Presidente: Nome:

Instituição:

Assinatura: 


\section{PATRÍCIA MARIA RODRIGUES GONÇALVES}

\section{COMO AS DEMARCAÇÕES NA TELA INFLUENCIAM A MANIFESTAÇÃO DO EFEITO ATENCIONAL AUTOMÁTICO}

Dissertação apresentada ao Instituto de Psicologia da Universidade de São Paulo para obtenção do título de Mestre em

Ciências

Área de Concentração: Neurociência e Comportamento

Orientadora: Profa. Dra. Mirella Gualtieri 
São Paulo, 01 de outubro de 2013.

\section{PARECER 1141/CEP}

A Comissão de Ética em Pesquisas em Seres Humanos do ICB, na reunião realizada no dia 25.09.2013, APROVOU o projeto intitulado: "Como as demarcações na tela influenciam a manifestação do efeito atencional automático" do pesquisador LuIz EdUARDo Ribeiro do VALLe e aluna PATRÍcia MARIA RODRIGUES GONÇALVES.

Cabe aos Pesquisadores executantes elaborar e apresentar a este Comitê, relatórios anuais (parciais ou final ), de acordo com a resolução 196/06 do Conselho Nacional da Saúde, item IX. 2 letra c. conforme modelo constante no site.icb.usp.br.

Ao pesquisador cabe também finalizar o processo junto à Plataforma Brasil quando do encerramento deste.

O primeiro relatório deverá ser encaminhado à Secretaria deste CEP em 25.09.2014.

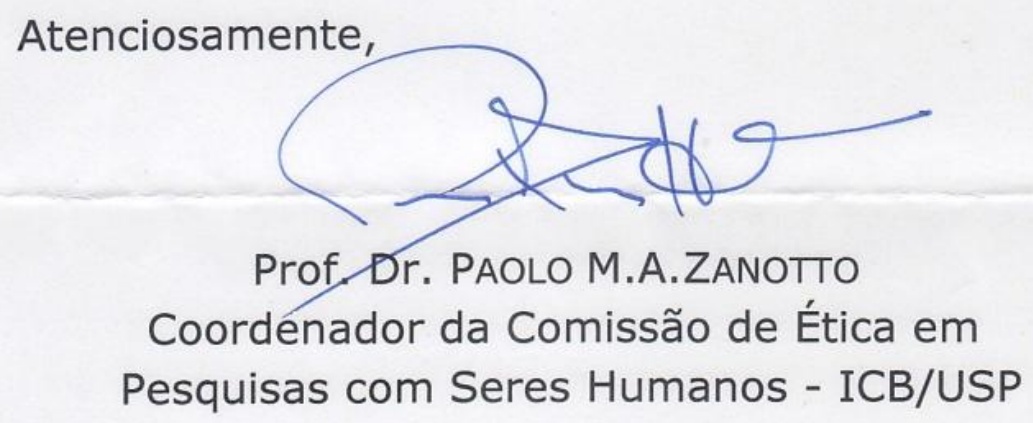


À minha mãe, Maria Guilhermina

Rodrigues Gonçalves (in memoriam), pelo amor eterno. 


\section{AGRADECIMENTOS}

À professora Mirella Gualtieri, por ter me auxiliado na segunda fase do meu mestrado, pela sua compreensão e orientação imprescindiveis para a conclusão desta dissertação;

Ao professor Luiz Eduardo Ribeiro do Valle, pela oportunidade e orientação dos experimentos;

Ao professor César Ades (in memoriam) por acreditar em meu potencial e me incentivar para o ingresso na carreira cientifica $e$ acadêmica;

À professora Fernanda Torello de Mello, pelas oportunidades e incentivos;

A todos os voluntários participantes dos experimentos, amigos e estudantes de Medicina da Universidade de São Paulo;

Á Capes, pelo apoio financeiro;

Aos meus amigos, Antônio Josefran, Monica Carranza e Maíra Valle, por me apoiarem e por estarem sempre presentes em minha vida;

À Thiago Dal Bello, pelas conversas, torcida e apoio constante;

À minha tia, Fátima Aparecida Rodrigues, pelo amor que me dedica, por ter se tornado minha segunda mãe e me apoiado integralmente durante todo o mestrado;

Ao meu irmão, Marcelo Rodrigues Gonçalves, minha cunhada, Fabiana Ramalho Gonçalves e minha sobrinha, Camila Ramalho Gonçalves, pelo carinho e suporte familiar;

Ao meu pai, João Manoel Gonçalves, pelo exemplo de caráter e pelo carinho e orgulho que me fazem ter forças para continuar;

E a todos que contribuíram para a realização deste trabalho. 
"O melhor uso da vida consiste em gastá-la por alguma coisa que dure mais que a própria vida." WILLIAM JAMES 


\section{RESUMO}

GONÇALVES, P.M.R. Como as demarcações na tela influenciam a manifestação do efeito atencional automático. 2015. (Mestrado em Neurociência e Comportamento) - Instituto de Psicologia, Universidade de São Paulo, São Paulo, 2015.

Em estudos sobre a atenção visuoespacial automática, as regiões de aparecimento dos estímulos são comumente demarcadas na tela. Resultados preliminares de nosso laboratório demonstraram que as demarcações favorecem a manifestação do efeito atencional. O presente estudo estendeu esse achado determinando o modo de atuação destes estímulos. Em um primeiro experimento, confirmamos o achado de que o efeito atencional observado quando as demarcações estão presentes diminui na ausência delas. Em um segundo experimento, investigamos a possibilidade do efeito atencional não se manifestar na ausência das demarcações devido a um desvio muito precoce do foco atencional do local inicialmente atendido, porém o efeito atencional não se manifestou na ausência das demarcações quando se estabilizou o foco atencional por um período maior no local atendido. No terceiro experimento, identificamos a possibilidade do efeito atencional não se manifestar na ausência das demarcações devido a um mascaramento anterógrado de determinado estímulo alvo pelo estímulo precedente mobilizador da atenção.

Palavras-chave: Neurociências, psicofísica, atenção automática, efeito atencional, atenção visuoespacial. 


\section{ABSTRACT}

GONÇALVES, P.M.R. How the placeholders on the screen influence the manifestation of automatic attentional effect. 2015. Master thesis. Instituto de Psicologia, Universidade de São Paulo, São Paulo, 2015.

In studies about automatic visuospatial attention, the appearance of the stimulus regions are commonly marked on the screen. Preliminary results from our laboratory demonstrated that the placeholders favors the development of attentional effect. This study extended this finding by determining the mode of action of these stimuli. In a first experiment, we confirmed the finding that the attencional effect observed when placeholders decreases in their absence. In a second experiment, we investigated the possibility of attentional effect do not manifest in the absence of placeholders due to a very early turning from the attentional focus of initially attended site, however, the attentional effect did not manifest in the absence of placeholders when it stabilized the attentional focus by a longer period in the treated site. In the third experiment, we identified the possibility of the attentional effect do not manifest in the absence of placeholders due to an anterograde masking of certain stimulus target by mobilizing previous stimulus of attention.

Passwords: Neuroscience, psychophysical, automatic attention, attentional efect, visuospatial attencion. 


\section{LISTA DE FIGURAS}

Figura 1: Vistas frontal e oblíqua dos equipamentos utilizados para a apresentação dos estímulos.

Figura 2: Sequência de eventos caracterizando cada uma das condições da Sessão 2 do Experimento 1.

Figura 3: Média dos tempos de reação para os Experimentos 1A e 1B (com e sem demarcação).

Figura 4: Média dos tempos de reação para os Experimentos 1A e 1B com análise comparativa entre os estímulos (quadrado e triângulo).

Figura 5: Comparaçação entre os resultados do Experimento $1 \mathrm{~B}$ e do Experimento 2.

Figura 6: Médias de tempo de reação comparanido os estímulos alvo quadrado e triângulo no Experimento 3. 


\section{LISTA DE ANEXOS}

Anexo A: Aprovação do Comitê de Ética em Pesquisas em Seres Humanos do Instituto de Ciências Biomédicas da Universidade de São Paulo.

Anexo B: Questionário de Edinburgh.

Anexo C: Instruções para a realização do Experimento $1 \mathrm{~A}$.

Anexo D: Instruções para a realização do Experimento 1B.

Anexo E: Instruções para a realização do Experimento 2.

Anexo F: Instruções para a realização do Experimento 3.

Anexo G: Termo de consentimento livre e esclarecido.

Anexo $\mathrm{H}$ : Teste de acuidade visual.

Anexo I: Teste Ishihara para daltonismo.

Anexo J: Tabela de dados do Experimento $1 \mathrm{~A}$, análise de condições mesma e oposta.

Anexo K: Tabela de dados do Experimento 1A, análise de condições mesma e oposta separados por estímulo (quadrado ou triângulo) e congruência da mão de resposta.

Anexo L: Tabela de dados do Experimento 1B, análise de condições mesma e oposta.

Anexo M: Tabela de dados do Experimento 1B, análise de condições mesma e oposta separados por estímulo (quadrado ou triângulo) e congruência da mão de resposta.

Anexo N: Tabela de dados do Experimento 2, análise de condições mesma e oposta.

Anexo 0: Tabela de dados do Experimento 2, análise de condições mesma e oposta separados por estímulo (quadrado ou triângulo) e congruência da mão de resposta.

Anexo P: Tabela de dados do Experimento 3, análise de condições mesma, oposta e neutra.

Anexo Q: Tabela de dados do Experimento 3, análise de condições mesma, oposta e neutra, separados por estímulo (quadrado ou triângulo) e congruência da mão de resposta. 


\section{SUMÁRIO}

1 INTRODUÇÃO.

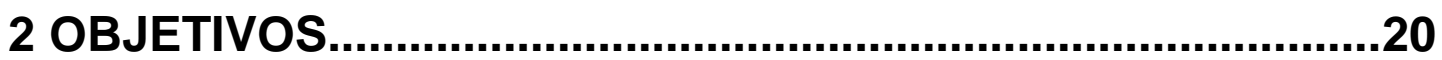

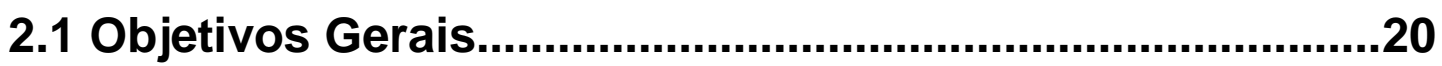

2.2 Objetivos Específicos......................................................20

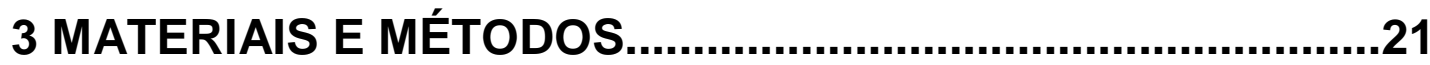

3.1 Participantes............................................................................21

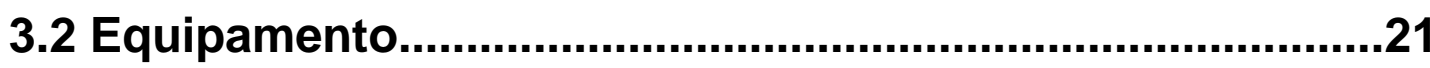

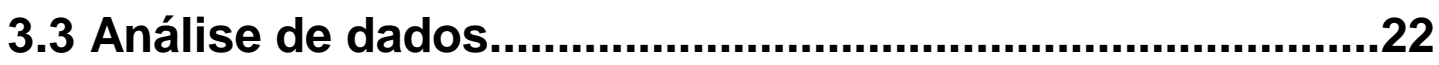

4 EXPERIMENTOS 1A E 1B..........................................................

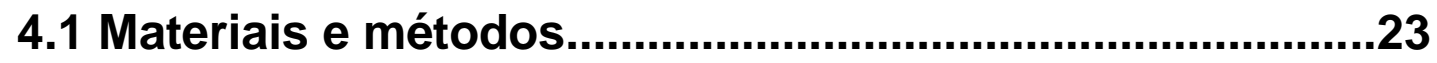

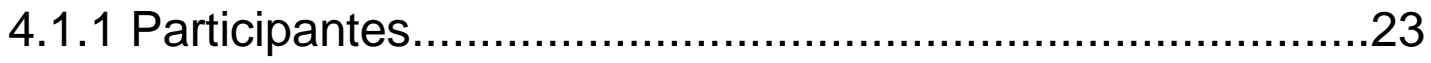

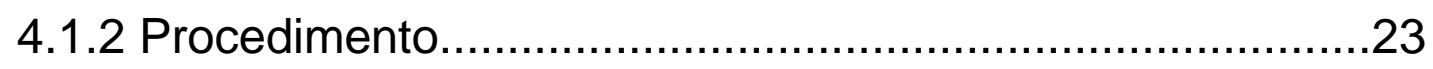

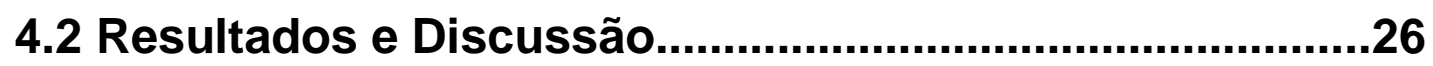

5 EXPERIMENTO 2

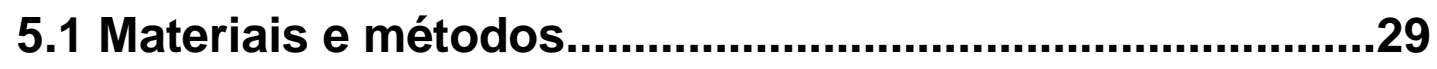

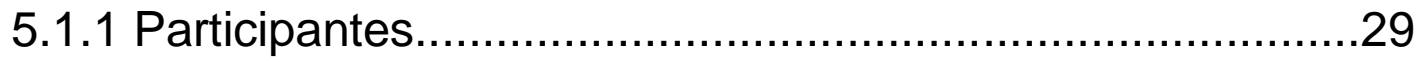

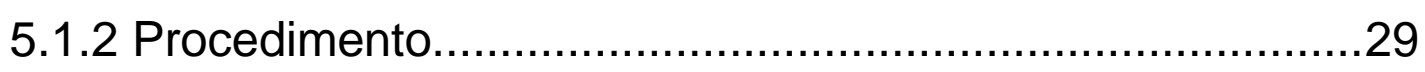

5.2 Resultados e Discussão....................................................30

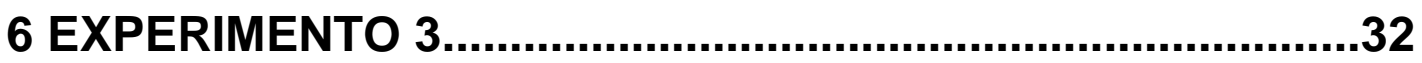

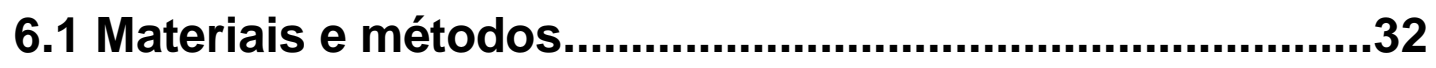

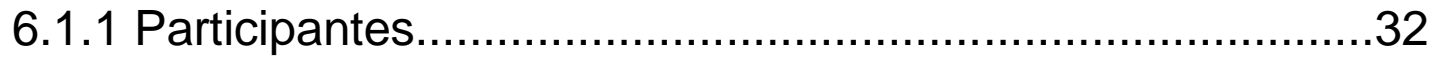

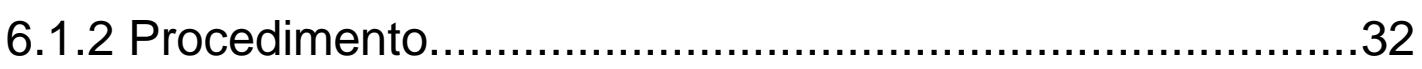


6.2 Resultados e Discussão.

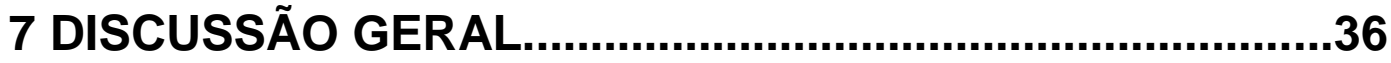

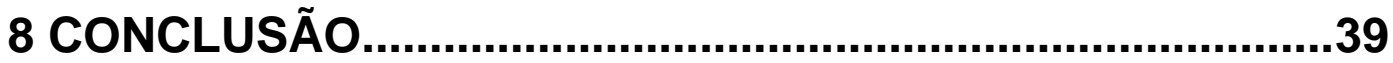

REFERÊNCIAS....................................................................40

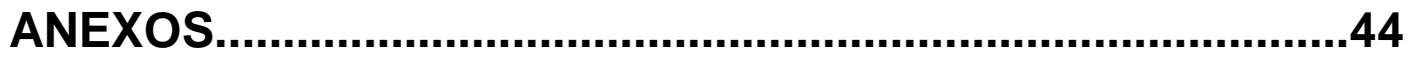




\section{INTRODUÇÃO}

A aprendizagem e a memória são consideradas processos cognitivos essenciais na definição do que somos e de como iremos interagir com o ambiente. O processo atencional age como um filtro na percepção de informações sensoriais, realizando uma seleção do que deve ser mantido e do que deve ser desconsiderado. Tanto na consolidação da memória explícita, quanto da implícita, existe uma seleção prévia executada pelo sistema atencional. As habilidades motoras também requerem um processo de filtragem de informações para que sejam aprendidas e executadas corretamente.

A atenção é descrita como um comportamento selecionado, por proporcionar grandes vantagens na sobrevivência de uma espécie em situações de forrageamento, caça, defesa contra predadores e seleção de um parceiro reprodutivo. Em um ambiente repleto de estímulos sensoriais competindo entre si, um sistema funcional que seja capaz de processar alguns estímulos com prioridade, outros com menor intensidade e, alguns, com pouca ou nenhuma relevância, é essencial para que não ocorra sobrecarga no sistema e, consequentemente, um gasto energético desnecessário.

Essa capacidade é evidente em nosso cotidiano quando, por exemplo, dirigimos um carro concentrados no percurso, com estímulos visuais periféricos processados minoritariamente, mas que, em algum momento, podem assumir a prioridade da situação ou, quando assistimos a uma aula e nosso sistema atencional se divide entre o professor e uma conversa entre colegas vizinhos na sala, alternando nosso foco prioritário atencional. Apesar de sermos conscientes dessa eficiência de processamento, as primeiras pesquisas científicas com ferramentas específicas para o estudo da atenção iniciaram-se no século XIX, com Hermann Helmholtz, em seus estudos de psicofisiologia. Helmholtz descobriu que poderia direcionar a mudança do foco atencional para uma área determinada, antes que houvesse o movimento ocular (WARREN e WARREN, 1968). Em seu experimento, o sujeito deveria manter os olhos em um ponto fixo central de um campo com letras. Em seguida, esse campo era 
iluminado pelo clarão repentino de uma faísca elétrica, mas a brevidade dessa iluminação impedia o movimento ocular. Dessa forma, o sujeito só conseguia identificar as letras que estavam no ponto de fixação, sem definição das que estavam ao redor. Entretanto, se previamente à apresentação da faísca, a atenção do sujeito era direcionada a um outro ponto específico do campo, as letras deste local eram reconhecidas. (WRIGHT e WARD, 1994).

Em 1890, William James descreveu a atenção, de acordo com a sua forma de orientação, em duas vertentes: atenção voluntária e involuntária ou automática.

A atenção voluntária é conscientemente alocada e considerada como fator importante para se concluir um objetivo. É também chamada como atenção ativa, com ação top-down, que é impulsionada por fatores que são internos ao observador (JAMES, 1890).

A atenção automática se manifesta independentemente da vontade do observador, provocado por algum estímulo ambiental, ainda que sua atenção voluntária esteja direcionada a outro assunto. É também chamada atenção exógena, determinada por um mecanismo bottom-up, que é disparado por estímulos externos ao observador (JAMES, 1890) .

Apesar da ampla divulgação da dicotomia dos termos bottom-up e topdown para classificar o controle da atenção, ainda existem alguns fatores que devem ser considerados em uma análise comportamental. Awh e colaboradores (2012) descreveram uma estrutura alternativa de definição da captação atencional, com três categorias distintas: (a) alvos determinados como metas para o cumprimento de determinada tarefa, em que existe o papel crítico da atenção voluntária; (b) história seletiva, com efeitos de experiências passadas que podem moldar o quadro de vieses de seleção do observador reforçando, assim, o papel da aprendizagem associativa e da memória na implantação da atenção e; (c) saliência física, que depende das propriedades do objeto, como, por exemplo, um círculo vermelho entre vários círculos brancos. 
Os estudos sobre atenção se tornaram mais efetivos a partir de meados do século $X X$, com a intensificação de experimentos realizados por pesquisadores como Colin Cherry (1953), Donald Broadbent (1958) e Ulric Neisser (1967). Broadbent (1958) apresentou a teoria do filtro atentivo, em que definiu o processamento de uma informação condicionado a dois momentos. No primeiro momento, os estímulos do ambiente seriam filtrados de acordo com sua relevância e saliência física e, no segundo momento, haveria o descarte dos elementos não relevantes. Diversas pesquisas subsequentes se nortearam nesta teoria para a investigação da atenção.

Posner e Boies (1971) dividiram e categorizaram o estudo da atenção em três componentes: o estado de alerta, a seletividade e a capacidade de processamento. $\mathrm{O}$ estado de alerta condiciona uma situação otimizada para o cumprimento de uma tarefa, ou seja, pistas ou sinais agindo em um tempo relativamente curto poderiam promover uma preparação do sistema nervoso para o processamento imediatamente posterior de determinada ação ou de informações relevantes. A seletividade pode estar associada a mecanismos de filtragem que bloqueiam ou atenuam a entrada de informações menos relevantes (BROADBENT, 1958) ou com a priorização e aumento de operações executadas na entrada de situações de importância para o indivíduo (NORMAN, 1968). A capacidade de processamento refere-se à limitação atencional na realização simultânea de duas tarefas, havendo interferência entre elas e ocasionando um tempo de reação maior para a realização de ambas.

$\mathrm{Na}$ investigação da atenção visual, o teste da atenção encoberta desenvolvido por Posner (1980) tem sido amplamente utilizado nos estudos sobre 0 assunto. $O$ procedimento padrão dessa tarefa determina que 0 voluntário fique posicionado em frente a um monitor, com olhar fixo em um ponto central. O sujeito é orientado a responder a determinados estímulos pressionando com as mãos os dispositivos de controle. No monitor, serão apresentadas pistas sinalizadoras antes dos estímulos-alvo; elas poderão aparecer no mesmo local do estímulo-alvo ou em local oposto. O tempo entre o aparecimento dos dois estímulos (pista e alvo) é caracterizado pela sigla SOA, 
stimulus onset asynchrony. Este procedimento básico é utilizado com algumas variáveis, de acordo com o interesse do estudo. Pode ser realizado com uma tarefa vai-não-vai (go no go) ou por discriminação de local de aparecimento e forma do objeto. Na tela, podem haver demarcações que indicam os locais de aparecimento dos estímulos.

Nestes estudos, baseados no clássico teste de Posner sobre atenção visuoespacial, os resultados demonstram que o tempo de reação a um estímulo alvo (E2) que aparece em um mesmo local que um estímulo precedente periférico não informativo espacialmente $(E 1)$ é menor que o tempo de reação a E2 aparecendo em local diferente de E1 (POSNER E COHEN, 1984; LUPIÁÑEZ et al., 2001; FOLK e REMINGTON, 2008). Este efeito é denominado efeito atencional e é máximo quando a assincronia entre o início do E2 e o início do E1 (AIE) é da ordem de $100 \mathrm{~ms}$. Esse tempo foi atribuído à mobilização automática da atenção pelo E1. A atenção facilitaria o processamento do E2 no local pré-estimulado e inibiria o processamento deste estímulo nos demais locais (PESTILLI e CARRASCO, 2005).

Considerando a mobilização automática da atenção por E1, esperariase que o efeito atencional (menor tempo de reação ao E2 quando no mesmo local do E1) fosse bastante robusto. No entanto, este não é o caso. Em muitas situações experimentais, o efeito atencional está completamente ausente (por exemplo, SQUELLA e RIBEIRO-DO-VALLE, 2003, Experimentos 1 e 2). $\mathrm{Na}$ última década, as condições necessárias para o aparecimento do efeito atencional têm sido investigadas em detalhes. Dentre os fatores importantes para o estabelecimento do efeito atencional, estão o tipo de tarefa realizada, a experiência prévia do indivíduo e a discriminabilidade do E2 (RUZ e LUPIÁÑEZ, 2002). o efeito atencional ocorre mais consistentemente em tarefas que requeiram a identificação do $E 2$ do que em tarefas que requeiram apenas a sua detecção (LUPIÁÑEZ et al., 2001; SQUELLA e RIBEIRO-DOVALLE, 2003). Mais que isso, a experiência prévia com a tarefa de detecção reduz 0 efeito atencional na tarefa de identificação (SQUELLA e RIBEIRO-DOVALLE, 2003). O efeito atencional é observado quando o E2 é mais difícil de discriminar, tanto quando se considera a diferenciação entre dois E2 (MACEA e RIBEIRO-DO-VALLE, 2006) como a diferenciação entre E2 e E1 (FOLK et al., 
1992; FOLK et al., 1994; FOLK e REMINGTON, 1998; FOLK e REMINGTON, 2008).

A demarcação dos locais de aparecimento dos estímulos na tela também parece ser importante para o estabelecimento do efeito atencional. $\mathrm{Na}$ maioria dos estudos evidenciando este efeito, os locais eram indicados por figuras geométricas (quadrados, círculos) vazios, seguindo o procedimento original utilizado por Posner e Cohen (1984). Resultados preliminares do nosso laboratório reforçam a ideia de que a presença das demarcações na tela é crítica para a obtenção do efeito atencional em pelo menos algumas condições estimulatórias. Brevemente, nenhum efeito atencional foi observado quando os estímulos (um anel cinza como E1 não informativo espacialmente e uma linha vertical ou uma cruz brancos como E2 vai e um pequeno anel branco como E2 não-vai) apareciam em uma tela vazia (FUGA, 2002), mas um efeito atencional importante ocorria quando anéis demarcavam os locais de aparecimento dos mesmos estímulos na tela (GUEDES, 2007).

Uma série de experimentos investigando de que forma as demarcações influenciam a manifestação do efeito atencional (SAIS e RIBEIRO-DO-VALLE, 2011) demonstraram que demarcações na tela 0 favorecem. Os resultados encontrados sugeriram que o efeito da demarcação é devido, pelo menos em parte, ao aumento da dificuldade de discriminar os E2 e consequente maior mobilização estratégica da atenção.

O efeito facilitador é identificado quando a atenção é guiada para o local correto por um estímulo precedente ao alvo, resultando em tempos de reação menores na realização da tarefa. No entanto, existe uma interação sensorial no processamento do estímulo precedente e do alvo que, em alguns casos, pode ocasionar uma perda de sensibilidade por padrão. Neste caso, ao invés de agir como facilitador no desempenho do teste, o estímulo precedente atuaria como uma máscara dificultando a sensibilização para o alvo e, consequentemente, gerando tempos de reação maiores para a concretização da tarefa. Este fenômeno, conhecido como mascaramento (BREITMEYER, 1984), age como redutor da visibilidade e pode alterar a percepção das características de um estímulo. O mascaramento pode ser considerado 
anterógrado ou retrógrado, de acordo com o momento em que é apresentado o estímulo mascarador no teste, antes ou depois do estímulo alvo (KAHNEMAN, 1968).

O fato de que as demarcações na tela facilitaram o aparecimento do efeito atencional em experimentos anteriores, nos leva à hipótese de que elas poderiam atuar diminuindo o mascaramento anterógrado entre o estímulo precedente e o alvo. Além disso, as demarcações atuariam como âncoras, captando a atenção espacialmente para os locais de aparecimento dos alvos.

Neste estudo, investigamos evidências adicionais com a intenção de esclarecer o mecanismo que torna as demarcações na tela um ponto crítico para o aparecimento do efeito atencional. 


\section{OBJETIVOS}

\subsection{Objetivos Gerais}

O objetivo deste trabalho foi analisar o estabelecimento do efeito atencional em diferentes situações com presença e ausência de demarcações na tela.

\subsection{Objetivos Específicos}

1- Confirmar os achados encontrados anteriores de que a ausência de demarcações na tela fazem com que o efeito atencional seja suprimido.

2- Investigar se a supressão do efeito atencional quando não existem demarcações na tela, deve-se a um desvio precoce do foco atencional no local anteriormente atendido.

3- Esclarecer as diferenças de efeito atencional entre estímulos alvo diferentes e um possível mascaramento anterógrado provocado pelo estímulo precedente. 


\section{MATERIAIS E MÉTODOS}

\subsection{Participantes}

Foram realizados quatro experimentos com um total de 48 voluntários adultos jovens, com faixa etária de 18 a 30 anos, com visão normal ou corrigida com óculos para o normal, de ambos os sexos. Nenhum deles teve conhecimento prévio da finalidade do estudo. Deste total de sujeitos, foram testados 24 voluntários nos experimentos IA e IB, 12 no experimento II e 12 no experimento III.

O estudo foi submetido e aprovado pela Comissão de Ética para Pesquisa com Seres Humanos do Instituto de Ciências Biomédicas da Universidade de São Paulo (Anexo A). Todos os participantes assinaram um termo de consentimento (Anexo B).

\subsection{Equipamento}

Os testes foram realizados em uma sala ventilada, com iluminação reduzida e certo isolamento acústico. Estímulos visuais foram apresentados aos participantes, que responderam a esses estímulos utilizando duas teclas posicionadas nas laterais (Figura 1). A geração dos estímulos e o registro das respostas foram realizados por um microcomputador IBM-PC/AT 486 e um programa elaborado com o aplicativo Micro Experimental Laboratory - MEL2 (Mel Professional 2.01 - Psychology Software Tools, EEUU). 

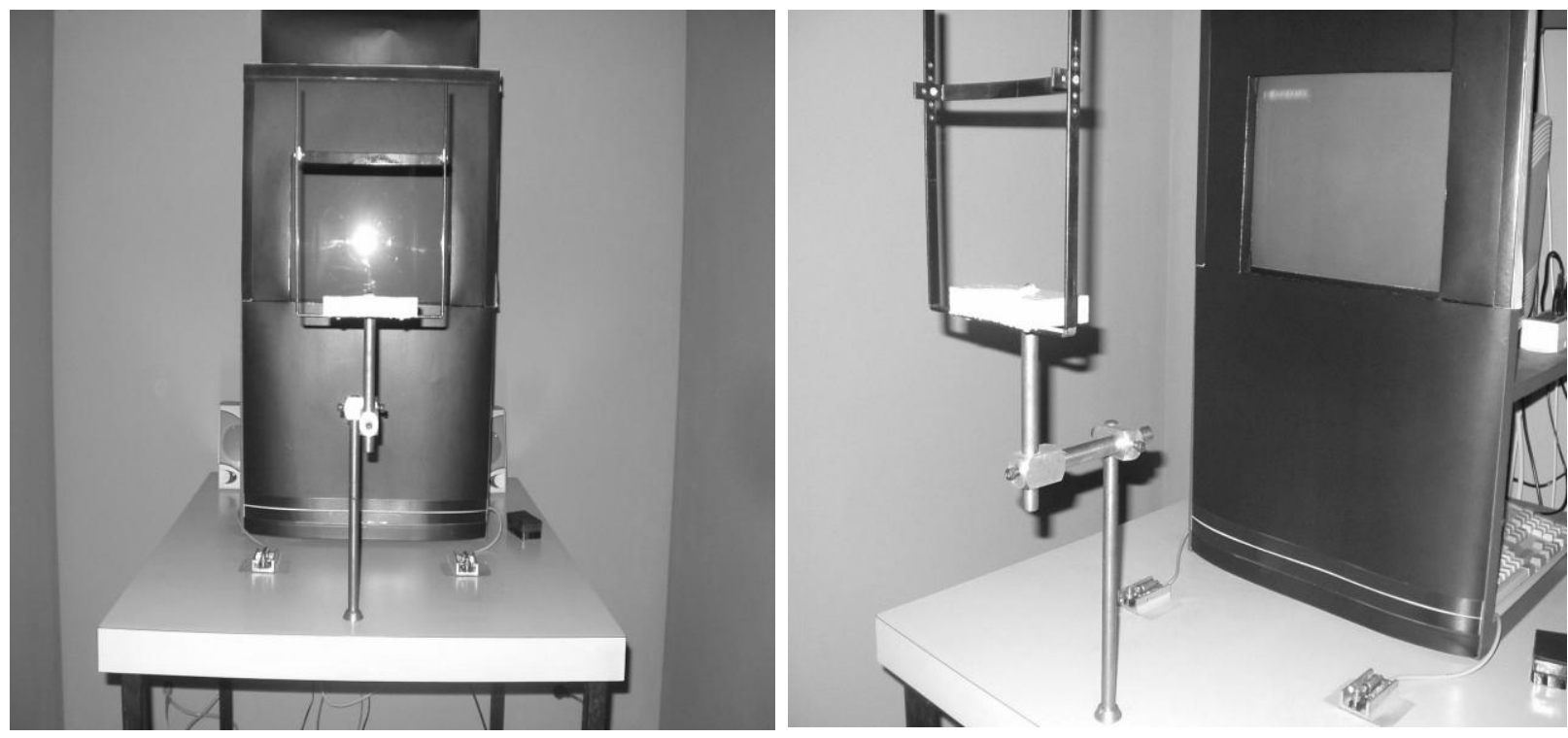

Figura 1. Vistas frontal e oblíqua dos equipamentos utilizados para a apresentação dos estímulos e o registro das respostas. Em primeiro plano pode-se ver o apoiador de fronte e mento. Em segundo plano, observam-se as duas teclas de resposta sobre a mesa e, em terceiro plano, o teclado do computador, o monitor de vídeo e o gabinete do computador, dispostos em uma estante metálica. Uma folha de cartolina preta limita o campo de visão do observador à tela do monitor.

\subsection{Análise de dados}

Os dados de tempo de reação foram verificados por meio de análises de variância para medidas repetidas. O teste de Newman-Keuls foi utilizado para as análises post hoc dos dados. Foi adotado o nível de significância de $5 \%$ em todas as análises estatísticas. 


\section{EXPERIMENTOS 1A E 1B}

Os experimentos 1A e 1B foram realizados para confirmar se a ausência de demarcações na tela nos locais onde irão aparecer os estímulos alvo faz com que o efeito atencional seja reduzido (como observado por SAIS e RIBEIRO-DO-VALLE, 2011).

\subsection{Materiais e métodos}

\subsubsection{Participantes}

Foram testados 24 voluntários adultos jovens, com média de idade de 20 anos e faixa etária de 18 a 27 anos, com visão normal ou corrigida com óculos para o normal, de ambos os sexos (13 homens e 11 mulheres). Nenhum deles teve conhecimento prévio da finalidade do estudo.

\subsubsection{Procedimento}

Os dois experimentos são idênticos, com uma única diferença entre eles: em 1A existem demarcações e em 1B a tela não é demarcada.

Cada voluntário realizou duas sessões de teste separadas por um intervalo de $5 \mathrm{~min}$. A primeira sessão foi constituída de 2 blocos de 32 tentativas e teve por finalidade treinar o voluntário para a tarefa. A segunda sessão foi constituida de 4 blocos de 64 tentativas e teve por finalidade medir 0 desempenho do voluntário na tarefa.

No primeiro bloco da primeira sessão, cada tentativa iniciou-se com o aparecimento de um ponto de fixação (PF) ocular central na tela cinza escuro do monitor (luminância de $0.09 \mathrm{~cd} / \mathrm{m}^{2}$ ). Entre 1750 e $2250 \mathrm{~ms}$ depois, era apresentado o estímulo alvo (E2) 9 graus à esquerda ou à direita do PF. Este E2 podia ser um quadrado branco medindo $5^{\circ}$ de lado ou um triângulo equilátero branco medindo $7^{\circ}$ de lado, ambos com luminância de $13,76 \mathrm{~cd} / \mathrm{m}^{2} \mathrm{e}$ duração de 50 ms (Figura 2). O lado de aparecimento do E2 e a sua forma variavam aleatoriamente e com igual probabilidade. A tarefa do voluntário era 
de responder tão rápido quanto possível ao quadrado com o dedo indicador esquerdo/direito e ao triângulo com o dedo indicador direito/esquerdo. A tentativa terminava com uma mensagem durando $400 \mathrm{~ms}$ no local do PF. O tempo de reação em milissegundos aparecia quando o voluntário respondia entre 150 e 1000 ms após o início do E2. As mensagens "ANTES", "LENTA" e "TROCA" apareciam quando o voluntário respondia antes de $150 \mathrm{~ms}$ do início do E2, não respondia em até $1000 \mathrm{~ms}$ do início do E2 ou, então, respondia com o dedo indevido entre 150 e 1000 ms após o início do E2, respectivamente. As tentativas erradas eram repostas.

No segundo bloco da primeira sessão as tentativas eram semelhantes às do primeiro bloco, porém com uma diferença, $100 \mathrm{~ms}$ antes do início do E2, aparecia um estímulo precedente (E1), representado por um anel cinza claro ( $1,5^{\circ}$ de diâmetro e $0,05^{\circ}$ de borda), com luminância de $3,15 \mathrm{~cd} / \mathrm{m}^{2}$ (Figura 2). Este E1 aparecia na posição de ocorrência do E2 subsequente em $50 \%$ das tentativas e na posição simétrica do lado oposto nos outros $50 \%$ das tentativas, de modo aleatório.

$\mathrm{Na}$ segunda sessão, as tentativas eram semelhantes às do segundo bloco da primeira sessão. De diferente, as tentativas terminavam com um asterisco rosa ou com um asterisco vermelho durando $200 \mathrm{~ms}$ no local do PF. O asterisco indicava que o voluntário respondeu corretamente e entre 150 e 1000 ms após o início do E2. O asterisco vermelho indicava que o voluntário respondeu antes de $150 \mathrm{~ms}$ do início do E2, não respondeu até $1000 \mathrm{~ms}$ do início do E2 ou, então, respondeu com o dedo indevido entre 150 e 1000 ms após o início do $\mathrm{E} 2$, respectivamente. As tentativas erradas eram repostas.

A diferença entre os experimentos $1 \mathrm{~A}$ e $1 \mathrm{~B}$ foi a demarcação nos locais da tela em que apareceriam os estímulos por anéis cinza médio $\left(0.58 \mathrm{~cd} / \mathrm{m}^{2}\right)$, que estava presente apenas no experimento 1A. (Figura 2) 

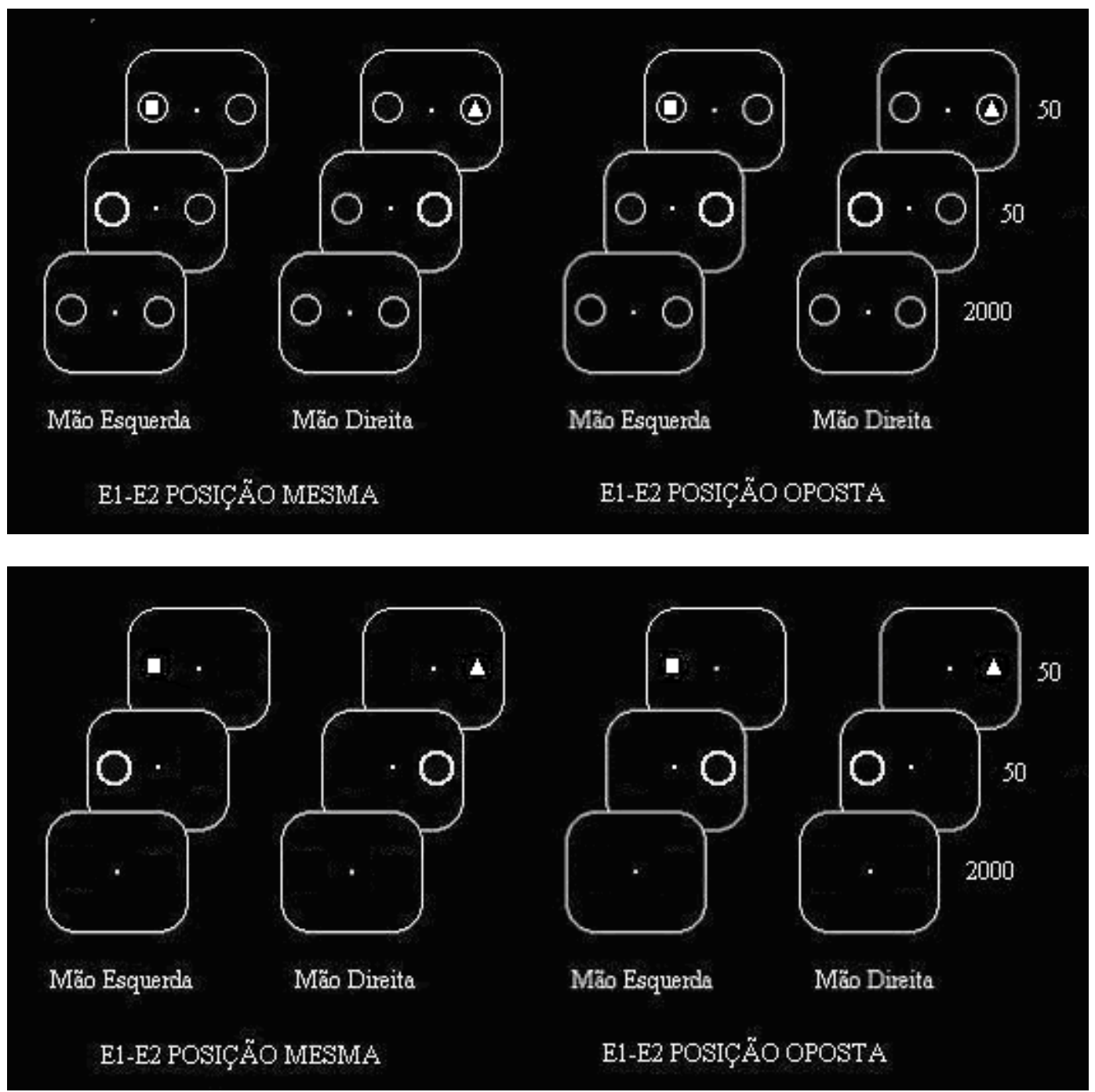

Figura 2 - Sequência de eventos caracterizando cada uma das condições da Sessão 2 do Experimento 1 . Os estímulos apareceriam $9^{\circ}$ à esquerda ou à direita do ponto de fixação central. A cor de fundo da tela era cinza escuro $\left(0,09 \mathrm{~cd} / \mathrm{m}^{2}\right)$ e o ponto de fixação era branco $\left(13,76 \mathrm{~cd} / \mathrm{m}^{2}\right)$. O estímulo precedente (E1) era cinza claro $(3,15$ $\left.\mathrm{cd} / \mathrm{m}^{2}\right)$ e durava $50 \mathrm{~ms}$. O estímulos alvos (E2) eram brancos $\left(13,76 \mathrm{~cd} / \mathrm{m}^{2}\right)$ e duravam 50 ms. O quadrado aparecia em $50 \%$ das tentativas e o triângulo em $50 \%$ das tentativas, randomicamente. A assincronia entre o início do E1 e do E2 foi de $100 \mathrm{~ms}$. Em 50\% das tentativas o E2 aparecia na mesma posição que o E1 (E1-E2 posição mesma) e em $50 \%$ das tentativas, na posição oposta (E1-E2 posição oposta), randomicamente. No Experimento $1 \mathrm{~A}$ as posições de aparecimento dos estímulos foram demarcadas por anéis cinza médio $\left(0,58 \mathrm{~cd} / \mathrm{m}^{2}\right)$ (painel superior) e no Experimento 1B estas posições não foram demarcadas (painel inferior). 


\subsection{Resultados e Discussão}

No experimento $1 \mathrm{~A}$, o tempo médio de reação para a resposta ao estímulo alvo (E2) que aparecia na posição mesma do estímulo precedente (E1) foi de $450 \mathrm{~ms}$, enquanto que, quando E2 aparecia na posição oposta ao $\mathrm{E} 1$, o tempo de reação foi de $482 \mathrm{~ms}$.

Portanto, o efeito atencional (EA) que se caracteriza pela diferença entre os tempos de reação ao estímulo alvo quando aparece na posição oposta (PO) de quando aparece na posição mesma (PM), foi de $32 \mathrm{ms.}$

$$
\mathrm{EA}=\mathrm{TR} P \mathrm{PO}-\mathrm{TR} \mathrm{PM}, \text { portanto, } \mathrm{EA}=482 \mathrm{~ms}-450 \mathrm{~ms}=\mathbf{3 2} \mathrm{ms} .
$$

A análise de variância demonstrou efeito significativo para a diferença na posição em que o alvo foi apresentado $(F ; p<0,001)$.

No experimento 1B, o tempo médio de reação para a resposta ao estímulo alvo (E2) que aparecia na posição mesma do estímulo precedente (E1) foi de $473 \mathrm{~ms}$, enquanto que, quando E2 aparecia na posição oposta ao $\mathrm{E} 1$, o tempo de reação foi de $488 \mathrm{~ms}$.

$$
E A=488 m s-473 \mathrm{~ms}=15 \mathrm{~ms} .
$$

$O$ efeito atencional está presente nos experimentos $1 \mathrm{~A}$ (com demarcação) e 1B (sem demarcação), porém é mais consistente em $1 \mathrm{~A}$ $(p<0,001)$ do que em 1B $(p=0,05)$, conforme figura 3 . 


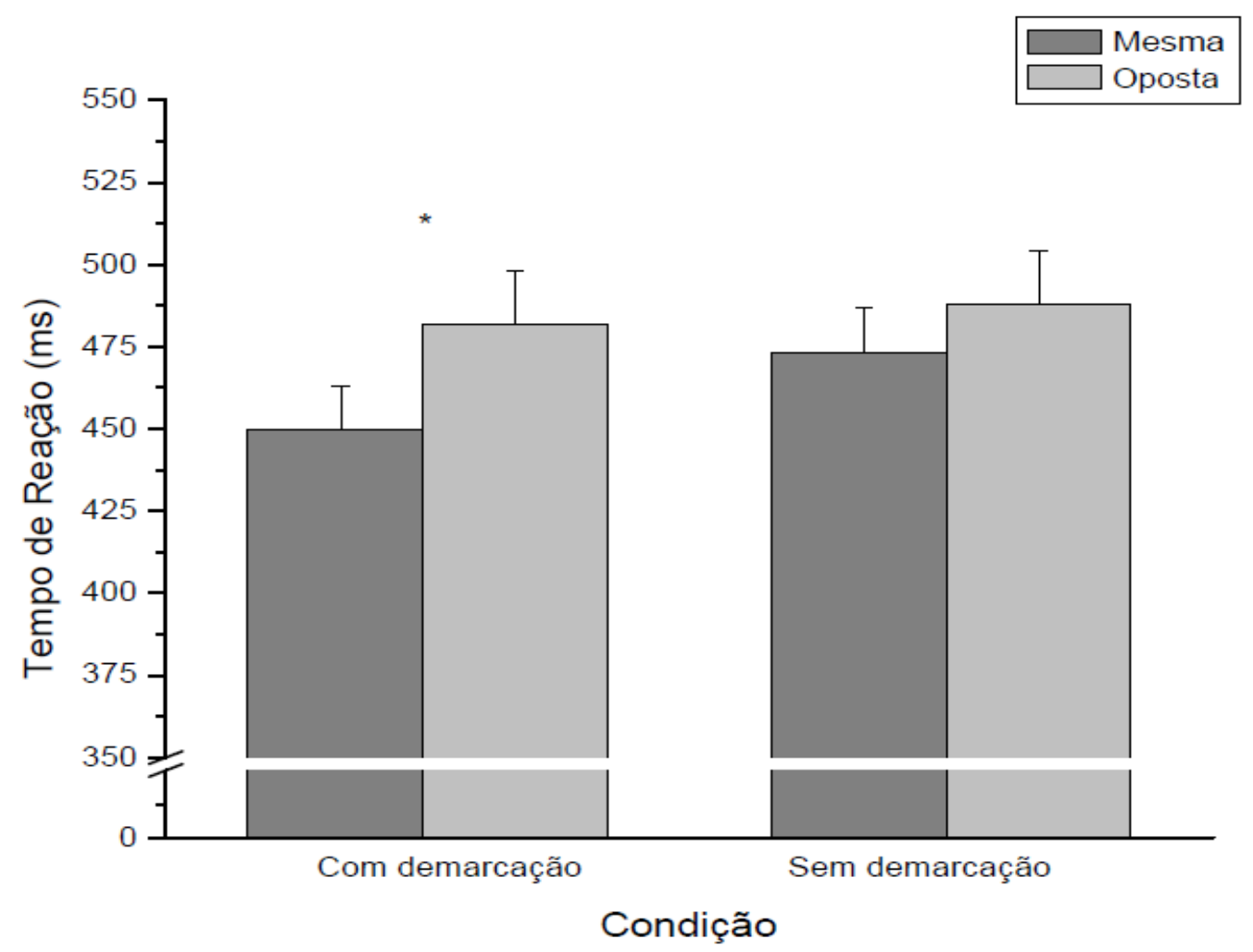

Fig. 3 - Média dos tempos de reação para os experimentos 1A e 1B (com e sem demarcação).

A análise foi estendida ao tempo de reação de acordo com e estímulo alvo E2 (quadrado ou triângulo).

$\mathrm{O}$ efeito atencional no experimento $1 \mathrm{~A}$ é significativo tanto para o $\mathrm{E} 2$ quadrado, quanto para o E2 triângulo. Porém, no experimento $1 \mathrm{~B}$, continua existindo efeito atencional para o quadrado, mas, para o triângulo, o efeito é inexistente, conforme figura 4. 

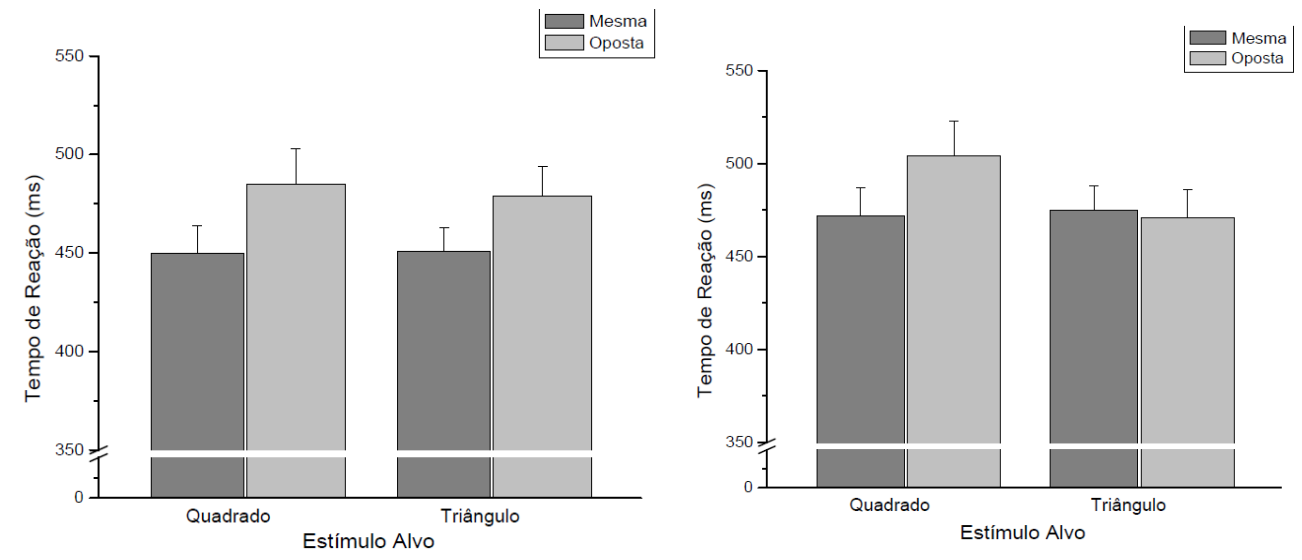

Fig. 4 - Média dos tempos de reação dos Experimentos 1A e !B com análise comparativa entre os estímulos (quadrado e triângulo). No primeiro gráfico, do experimento $1 \mathrm{~A}$, pode ser observado efeito atencional para os estímulos alvo quadrado e triângulo de $35 \mathrm{~ms}$ e $28 \mathrm{~ms}$, respectivamente. No segundo gráfico, do experimento 1B (sem demarcação na tela), observa-se o efeito atencional para 0 estímulo alvo quadrado de $32 \mathrm{~ms}$, porém, para o triângulo, o efeito desaparece.

O resultado confirma o estudo anterior de Sais e Ribeiro-do-Valle (2011) de que as demarcações na tela poderiam favorecer o efeito atencional, testando as condições com demarcação e sem demarcação, mesmo com algumas condições experimentais diferentes, utilizando fundo de tela cinza escuro em vez de branco, e com o E1 durando $50 \mathrm{~ms}$ em vez de $34 \mathrm{~ms}$, e E2 representado por um quadrado e um triângulo em vez de uma linha vertical e um anel pequeno.

Esses dados podem indicar que a demarcação age como um facilitador na execução da tarefa, pois os tempos de reação são menores quando ela está presente no teste. Entretanto, um fator importante a ser considerado, é que o efeito atencional deixa de existir sem a demarcação, mas apenas para um tipo de estímulo alvo, o triângulo.

A combinação das demarcações com o estímulo precedente nos casos em que o triângulo é o alvo favorece o efeito atencional, porém quando um dos componentes é retirado, o efeito desaparece. Na situação em que o quadrado é o alvo, a exclusão das demarcações na tela não altera o efeito atencional. 


\section{EXPERIMENTO 2}

Para uma melhor análise do papel da demarcação no efeito atencional, foi necessário realizar um segundo experimento sem demarcação, porém com duração maior do E1 (100ms em vez de $50 \mathrm{~ms}$ ). Dessa forma, poderia ser verificado se, com um tempo maior na tela, o E1 não teria a função de âncora, segurando a atenção do voluntário para o local atendido por mais tempo.

\subsection{Materiais e métodos}

\subsubsection{Participantes}

Foram testados 12 voluntários adultos jovens, com média de idade de 20 anos e faixa etária de 18 a 27 anos, com visão normal ou corrigida com óculos para o normal, de ambos os sexos (4 homens e 8 mulheres). Nenhum deles teve conhecimento prévio da finalidade do estudo.

\subsubsection{Procedimento}

O experimento 2 é semelhante ao experimento $1 \mathrm{~B}$, com uma única diferença, o E1 teve duração de 100 ms e não mais de 50 ms. 


\subsection{Resultados e Discussão}

No experimento 2, o tempo médio de reação para a resposta ao estímulo alvo (E2) que aparecia na posição mesma do estímulo precedente (E1) foi de $492 \mathrm{~ms}$, enquanto que, quando E2 aparecia na posição oposta ao $\mathrm{E} 1$, o tempo de reação foi de $512 \mathrm{~ms}$.

Portanto, o efeito atencional (EA) que se caracteriza pela diferença entre os tempos de reação ao estímulo alvo quando aparece na posição oposta (PO) de quando aparece na posição mesma (PM), foi de $20 \mathrm{~ms}$.

$$
E A=T R P O-T R P M, \text { portanto, } E A=512 \mathrm{~ms}-492 \mathrm{~ms}=\mathbf{2 0} \mathrm{ms} \text {. }
$$

Conforme figura 5, o resultado em relação ao efeito atencional de acordo com o estímulo alvo foi semelhante ao encontrado do experimento $1 \mathrm{~B}$. Para o quadrado, o efeito atencional foi de $24 \mathrm{~ms}$ e, para o triângulo, o efeito não é significativo. 


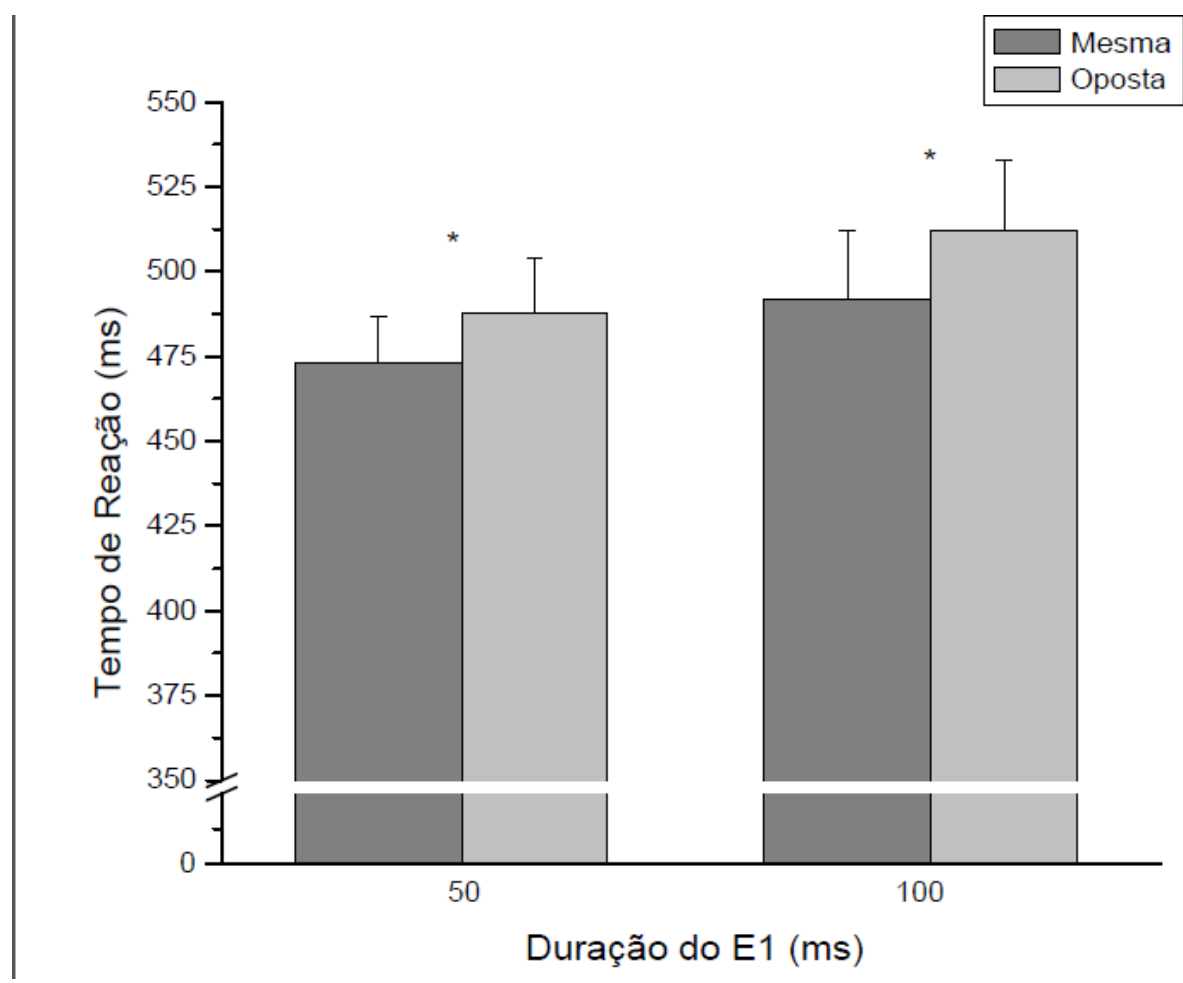

Figura 5. Comparação entre os resultados do Experimento 1B (100 ms) e do Experimento 2 (50 ms), em que não houve diferença significativa no aparecimento do efeito atencional $(p=0,10)$.

A diferença no aparecimento do efeito atencional entre o experimento 1B e o experimento 2 não foi significativa $(p=0,10)$, sendo assim, a hipótese de que E1 agiria como uma âncora, captando a atenção para o local atendido foi descartada.

Nesse experimento, foi possível confirmar que existe uma diferença no processamento atencional entre estímulos diferentes. 


\section{EXPERIMENTO 3}

Com o objetivo de esclarecer a ação dos estímulos precedente e alvo durante $o$ aparecimento do efeito atencional $e$ as diferenças de processamento entre o quadrado e o triângulo, foi realizado o experimento 3. Neste experimento, foi incluída uma nova condição, neutra, sem o aparecimento do E1. Assim, poderíamos obter informações esclarecedoras sobre a ação do E1 e se ele atuaria como um fator inibidor ou facilitador na execução da tarefa.

\subsection{Materiais e métodos}

\subsubsection{Participantes}

Foram testados 12 voluntários adultos jovens, com média de idade de 21 anos e faixa etária de 18 a 26 anos, com visão normal ou corrigida com óculos para o normal, de ambos os sexos (5 homens e 7 mulheres). Nenhum deles teve conhecimento prévio da finalidade do estudo.

\subsubsection{Procedimento}

As condições experimentais do Experimento 3 foram idênticas às do Experimento 1B, com duas exceções:

- Primeira, um tom de $300 \mathrm{~Hz}$ com intensidade de $57 \mathrm{~dB}$ e duração de $50 \mathrm{~ms}$ ocorria $500 \mathrm{~ms}$ antes do E2 em todas as tentativas da primeira e segunda sessões (este estímulo foi utilizado para garantir que nas tentativas sem o $\mathrm{E} 1$ a atenção temporal atue da mesma forma que nas tentativas com o E1, permitindo que qualquer diferença nos seus tempos de reação possa ser atribuída à ocorrência da influência atencional espacial ou mascaradora do E1). 
. Segunda. o estímulo precedente E1 aparecia apenas em 2 blocos da segunda sessão. Para metade dos voluntários, aparecia no primeiro e terceiro blocos e não aparecia no segundo e quarto blocos. Para a outra metade dos voluntários, era alternada a ordem de aparecimento do E1 nos blocos.

Dessa forma, nos blocos em que não aparecia o $\mathrm{E} 1$, foi criada uma condição neutra. 


\subsection{Resultados e Discussão}

O tempo médio de reação para a resposta ao estímulo alvo (E2) que aparecia na posição mesma do estímulo precedente (E1) foi de $437 \mathrm{~ms}$, enquanto que, quando E2 aparecia na posição oposta ao E1, o tempo de reação foi de $450 \mathrm{~ms}$. Para a nova condição neutra, sem E1, o tempo de reação foi de $412 \mathrm{~ms}$. Em relação ao resultado das posições mesma e oposta, a análise de variância indicou um efeito atencional reduzido ( $p=0,04)$, assim como nos experimentos 1B e 2. A comparação entre a posição neutra tanto com a oposta, como com a mesma, foi significativa $(p<0,01)$.

Analisando os tempos de reação de acordo com os estímulos alvo, o resultado é condizente com os experimentos $1 \mathrm{~B}$ e 2, pois o efeito atencional para o quadrado permanece, enquanto que, para o triângulo, não é significativo (Figura 6).

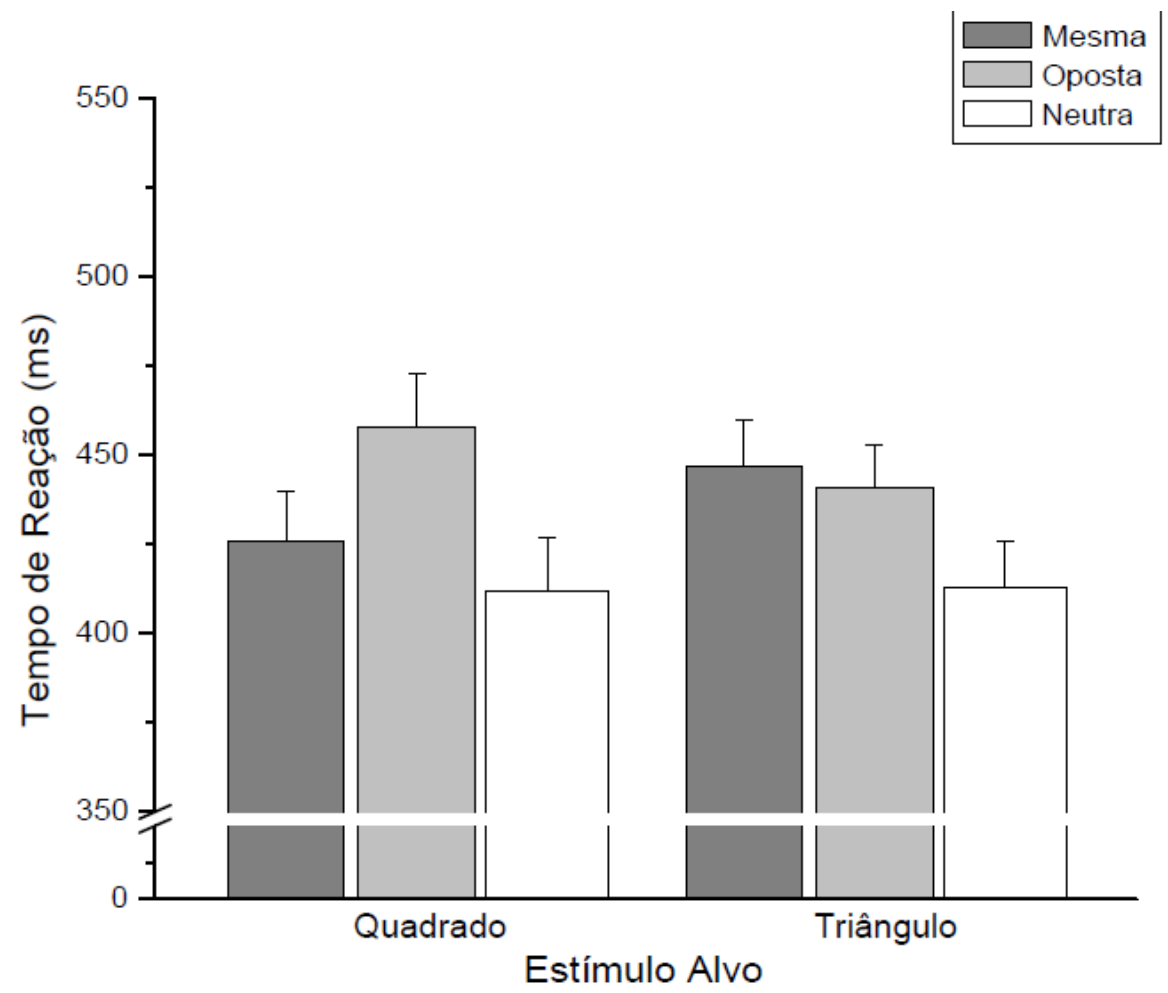

Fig. 6 - Médias de tempo de reação comparando os estímulos alvo quadrado e triângulo no Experimento 3, confirmam o efeito atencional para o primeiro e a ausência de efeito para o segundo. $O$ tempo de reação da condição neutra (sem E1) é o mesmo para os dois estímulos. 
Para o estímulo alvo quadrado, os tempos de reação foram: 426ms para a posição mesma, $458 \mathrm{~ms}$ para a posição oposta e $412 \mathrm{~ms}$ para a neutra. Com o triângulo, obtivemos: $447 \mathrm{~ms}$ para a posição mesma, 441 para a posição oposta e $413 \mathrm{~ms}$ para a neutra. O efeito atencional foi claramente observado na tarefa com o quadrado $(p<0,01)$ e decresceu para o triângulo $(p=0,04)$. Para as duas figuras geométricas, a tarefa sem a apresentação de estímulo precedente (neutra) foi executada com o mesmo tempo de reação $(p<0,01)$.

Estes resultados foram condizentes em todos os experimentos. Neste último, encontramos uma informação adicional, indicando que, neste tipo de prova de detecção destas formas geométricas específicas e sem demarcações na tela, a presença do estímulo precedente aumenta o tempo de reação para a finalização da tarefa. 


\section{DISCUSSÃO GERAL}

Neste estudo, demonstramos que o estímulo precedente não age sempre como facilitador na realização de uma tarefa, mesmo quando indica a localização correta do aparecimento do alvo. No Experimento 3, os resultados indicaram que, em uma condição neutra, os tempos de reação são menores do que na condição em que o estímulo precedente aparece.

Com o experimento 3 , houve também a confirmação de que o estímulo precedente age de maneiras diferentes de acordo com a forma do estímulo alvo. Para a forma de quadrado, ele facilita a resposta quando aparece na posição mesma e inibe quando aparece na posição oposta. Para a forma de triângulo, o E1 parece ter somente um efeito inibitório quando aparece em qualquer das duas posições. A condição neutra, sem E1, confirma o seu efeito inibitório.

Uma hipótese que justificaria esse achado é a de que na interação da pista com um estímulo alvo específico, poderia ocorrer um mascaramento anterógrado do alvo e o efeito atencional poderia agir com menor eficácia para determinado estímulo (KEYSERS e PERRET, 2002; MACNICK e LIVINGSTONE, 1998). As demarcações na tela poderiam atenuar esse fenômeno, pois agiriam como âncoras da atenção do observador, facilitando relativamente a tarefa, mesmo quando existe um mascaramento anterógrado da figura do triângulo pelo estímulo precedente. Ao retirarmos essas demarcações, essa atenuação desaparece e o efeito atencional é inibido.

Lupiáñez e colaboradores (2001) argumentam que, mesmo que as pistas facilitem a captura da atenção para determinado local no espaço, esse efeito pode ser modulado endogenamente no comportamento de acordo com o processamento atencional de uma tarefa. Na discriminação entre dois alvos diferentes (triângulo e quadrado) poderia haver uma facilitação para uma figura e inibição para outra de acordo com a pista utilizada.

Schoeberl et. al. (2015) testaram em dois experimentos a relevância da pista para a detecção do estímulo alvo. A pista aparecia $16 \mathrm{~ms}$ antes do alvo, 
podendo piscar do mesmo lado do estímulo alvo (condição válida) ou do lado oposto (condição inválida). A cor da pista (círculo negro) era diferente dos alvos (coloridos). Os resultados demonstraram que o tempo de reação foi menor para a condição válida do que para a inválida e, até mesmo, para a neutra, quando esta terceira condição foi acrescentada no segundo experimento. Os autores sugerem que, nesta condição experimental em que é apresentada uma pista de cor diferenciada do alvo, o efeito atencional se manifesta claramente.

A saliência do alvo representa um papel crucial na captura atencional e depende do grau em que se destaca no ambiente (THEEUWES, 2004). Um elemento cercado por um grupo homogêneo de elementos contrastantes será mais saliente do que um elemento que está rodeado por um grupo menos homogêneo. Além disso, quanto mais próxima ao alvo estiver a pista, menos saliente ele se torna e o tempo de reação para a sua detecção será maior (DUNCAN e HUMPHREYS, 1989; THEEUWES et. al., 2004).

Existem etapas que compõem o ciclo percepção-ação nos organismos. Os fotorreceptores localizados na retina são estimulados pela luz com padrões específicos, que são decodificados para a construção da imagem de objetos, formas e espaços que determinam por inferência o mundo exterior (Spillman \& Werner, 1989; Palmer, 1999). Informações de maior relevância para o observador possuem um processamento prioritário, manifestando-se como a atenção. A atenção visual se processa com uma varredura do ambiente, identificando elementos relevantes ao sujeito (Folk et al., 1992; Ruz \& Lupianez, 2002). No presente estudo, não foi verificada prioridade de processamento para nenhum dos dois estímulos alvo, quadrado e triângulo.

Os tempos de reação para a condição neutra tanto no quadrado, como no triângulo, são equivalentes, o que descarta a possibilidade de que seja uma dificuldade maior de identificação apenas da figura geométrica. Há uma indicação de que na combinação do E1, precedido pelo E2 triângulo acontece uma inibição da resposta, pois os tempos de reação são maiores 
Comparando-se os experimentos $1 \mathrm{~A}$ com $1 \mathrm{~B}$ e 3 , onde o tempo de duração do $\mathrm{E} 1$ é o mesmo (50 ms), fica demonstrado que, quando existe demarcação na tela, os tempos de reação são menores e o E1 exerce efeito facilitador tanto para o quadrado, quanto para o triângulo. Quando a demarcação da tela é retirada, os tempos de reação aumentam e o efeito atencional permanece apenas para a figura do quadrado.

Os neurônios no sistema visual, além de competirem entre si pelo controle, possuem sistemas de inibição lateral que caracterizam 0 processamento da visão, favorecendo estímulos com maior contraste e luminância (Desimore e Duncan, 1995).

Uma hipótese para justificar o processamento diferenciado entre estímulos, poderia ser o mascaramento anterógrado que o E1 anel provocaria no E2 triângulo devido ao seu nível de luminância ser maior quando aparece na tela sem demarcação e que a figura do quadrado seria mais saliente, por ser composto por 4 retas e, portanto, não sendo inibida pelo E1.

Este estudo teve como objetivo inicial analisar o fenômeno da diminuição do efeito atencional quando ocorre a exclusão das demarcações na tela. Entretanto, um aprofundamento no tratamento dos dados brutos obtidos nos levou a achados específicos sobre como o processamento da atenção é suscetível a diversos fatores componentes de uma tarefa, $\mathrm{O}$ efeito atencional e os tempos de reação podem ser alterados pelas variáveis utilizadas nos experimentos: o formato dos estímulos precedentes e estímulos alvo e das demarcações, a assincronia de tempo de aparecimento entre eles, a luminância e a forma que a combinação de todos essas informações será processada. Essas descobertas foram consistentes e permaneceram na análise dos quatro experimentos realizados e, portanto, terão uma parcela de contribuição para futuros estudos, necessários para o esclarecimento deste sistema complexo. 


\section{CONCLUSÃO}

Os resultados encontrados no presente estudo indicam que 0 aparecimento do efeito atencional nos testes de Posner é influenciado pelos fatores adicionais apresentados nas tarefas.

A captura da atenção pode ser modulada de acordo com a apresentação e disposição de elementos no cenário observado. Demarcações na tela podem intensificar o efeito atencional de acordo com o estímulo alvo apresentado.

O estímulo precedente pode ser um fator de mascaramento para determinados estímulos alvo, como o triângulo, neutralizando, assim, o efeito atencional. 


\section{REFERÊNCIAS BIBLIOGRÁFICAS}

BREITMEYER, B. G. Visual masking: An integrative approach. New York: Oxford University Press, 1984.

BROADBENT, D. E. Perception and communication. London: Pergamon Press, 1958.

CHERRY, C. Some experiments on the recognition of speech with one and two ears. Journal of the Acoustical Society of America, v. 25, p. 975-979, 1953.

DESIMORE, R.; DUNCAN, J. Neural mechanisms of selective visual attention. Annual Review of Neuroscience, v.18, p.193-222, 1995.

DUNCAN, J.; HUMPHREYS, G.W. Visual search and stimulus similarity. Psychological Review, v. 96, p. 433-458, 1989.

FOLK, C.L.; REMINGTON, R.W.; JOHNSTON, J.C. Involuntary covert orienting is contingent on attentional control settings. Journal of Experimental Psychology: Human Perception and Performance, v. 18, p. 10301044, 1992.

FOLK, C.L.; REMINGTON, R.W.; WRIGHT, J.H. The structure of attentional control: Contingent attentional capture by apparent motion, abrupt onset, and color. Journal of Experimental Psychology: Human Perception and Performance, v. 20, p. 317-329, 1994.

FOLK, C.L.; REMINGTON, R.W. Selectivity in distraction by irrelevant featural singletons. Evidence for two forms of attntional capture. Journal of Experimental Psychology: Human Perception and Performance, v. 24, p.847858, 1998. 
FOLK, C.L.; REMINGTON, R.W. Bottom-up priming of top-down attentional control settings. Visual Cognition, v.16, p. 215-231, 2008.

FUGA, N.B. The influence of attention and forward masking on reaction time. Dissertation presented at the Institute of Biomedical Sciences of the University of São Paulo as partial requirement for obtaining the Master Degree in Science, 2002.

GUEDES, V.A. Inhibitory effects of a visual cue in reaction time tasks. Dissertation presented at the Institute of Biomedical Sciences of the University of São Paulo as partial requirement for obtaining the Master Degree in Science, 2007.

JAMES, W. The principles of psychology. (vol. 1) New York: Henry Holt \& Co, 1890.

KAHNEMAN, D. Method, findings and theory in studies of visual masking. Psychol. Bull., v. 70, p. 404-425, 1968.

KEYSERS, C.; PERRET, D. I. Visual masking and RSVP reveal neural competition. Trends in Cognitive Sciences, v. 6, n. 3, p. 120-125, 2002.

LUPIÁÑEZ, J.; MILLIKEN, B.; SOLANO, C.; WEAVER, B.; TIPPER, S.P. On the strategic modulation of the time course of facilitation and inhibition of return. The Quarterly Journal of Experimental Psychology, v. 54A, p. 753-773, 2001.

MACEA, D.D.; ABBUD, G.A.C.; LOPES-DE-OLIVEIRA, M.L.; FUGA, N.B.; RIBEIRO-DO-VALLE, L.E. Control of attention by a peripheral visual cue depends on whether the target is difficult to discriminate. Brazilian Journal of Medical and Biological Research, v. 39, p. 957-968, 2006. 
MACKNICK, S. L.; LIVINGSTONE, M. S. Neuronal correlates of visibility and invisibility in the primate visual system. Nature Neuroscience, v. 1, n. 2, p. 144-149, 1998.

NEISSER, U. Cognitive Psychology. Nova York: Appleton-Century Crofts, 1967.

NORMAN, D, A. Toward a theory of memory and attention. Psychological Review, v. 75, p. 522-536, 1968.

PALMER, S. E. Vision Science - photons to phenomology. Cambridge, Mass: MIT Press, 1999.

PESTILLI, F.; CARRASCO, M. Attention enhances contrast sensitivity at cued and impairs it at uncued locations. Vision Research, v. 45, p. 18671875, 2005.

POSNER, M. I.; COHEN, Y. Components of visual orienting. Bouma, H. \& Bouwhuis, G.G. (Ed.). Attention and performance. Hillsdale: Erlbaum. p. 531556, 1984.

RUZ, M.; LUPIÁÑEZ, J. A review of attentional capture: On its automaticity and sensitivity to endogenous control. Psicológica, v. 23, p. 283-309, 2002.

SCHOEBERL, T.; FUCHS, I. THEEUWES, J.; ANSORGE, U. Stimulus-driven attentional capture by subliminal onset cues. Attention, Perception, \& Psychophysics, v. 77, p. 737-748, 2015.

SPILLMAN, L.; WERNER, J.S. Visual perception: the neurophysiological foundations. San Diego, CA: Academic Press, 1989.

SQUELLA, S.A.; RIBEIRO-DO-VALLE, L.E.. Priming effects of a peripheral visual stimulus in simple and go/no-go tasks. Brazilian Journal of Medical and Biological Research, v. 36, p. 247-261, 2003. 
THEEUWES, J. Top-down search strategies cannot override attentional capture. Psychonomic Bulletin \& Review, v. 11, p. 65-70, 2004.

THEEUWES, J.; KRAMER, A.F.; KINGSTONE, A. Attentional capture modulates perceptual sensitivity. Psychonomic Bulletin \& Review, v..11(3), p. 551-554, 2004.

WARREN, R.M.; WARREN, R.P. Helmholtz on perception: Its physiology and development. New York: Wiley, 1968.

WRIGHT, R.D.; WARD, L.M. Shifts of Visual Attention: An Historical and Methodological Overview. Canadian Journal of Experimental Psychology, v. 48(2), p. 151-166, 1994. 
ANEXOS 


\section{ANEXO A}

\section{UNIVERSIDADE DE SÃO PAULO}

INSTITUTO DE CIÊNCIAS BIOMÉDICAS

Cidade Universitária "Armando de Salles Oliveira"

Cidade Universitaria 'Ar $2415-$ dep $05508-000$ Săo Paulo, SP - Brasil

Av. Prof. Lineu Prestes, 2415 - cep. 05508-000 São Paulo,

e-mail: cep@ icb.usp.br

São Paulo, 01 de outubro de 2013.

\section{PARECER 1141/CEP}

A Comissão de Ética em Pesquisas em Seres Humanos do ICB, na reunião realizada no dia 25.09.2013, APROVOU o projeto intitulado: "Como as demarcações na tela influenciam a manifestação do efeito atencional automático" do pesquisador luiz EduARDo RIbeiro do VALLe e aluna PATRícia MARIA RODRIGUES GONÇALVES.

Cabe aos Pesquisadores executantes elaborar e apresentar a este Comitê, relatórios anuais (parciais ou final ), de acordo com a resolução 196/06 do Conselho Nacional da Saúde, item IX. 2 letra c. conforme modelo constante no sitze.icb.usp.br.

Ao pesquisador cabe também finalizar o processo junto à Plataforma Brasil quando do encerramento deste.

O primeiro relatório deverá ser encaminhado à Secretaria deste CEP em 25.09.2014.

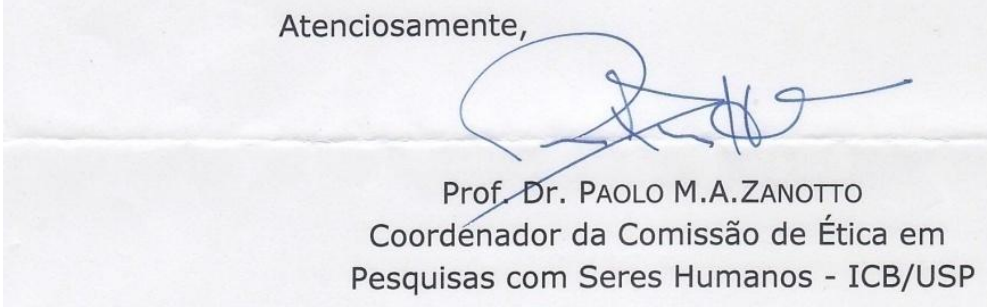

Comissão de Ética em Pesquisa com Seres Humanos do Instituto de Ciências Biomédicas / USP Aprovada pela Comissão Nacional de Ética em Pesquisa - CONEP, em 10 de fevereiro de 1998. 


\section{ANEXO B}

\section{Questionário de Edinburgh (adaptado)}

Nome

Idade anos

Você já teve alguma tendência a ser canhoto?

Existe algum canhoto na sua família?

Indicar a preferência manual nas atividades abaixo. Assinale ++ na coluna apropriada quando a preferência for tão forte que você nunca use a outra mão. Assinale ++ e + nas colunas apropriadas quando preferir usar uma das mãos mas de vez em quando também usar a outra. Assinale ++ nas duas colunas quando usar indistintamente qualquer uma das mãos.

\begin{tabular}{|l|l|l|}
\hline Atividades & Direita & Esquerda \\
\hline Escrever & & \\
\hline Desenhar & & \\
\hline Jogar uma pedra & & \\
\hline Usar uma tesoura & & \\
\hline Usar um pente & & \\
\hline Usar uma escova de dentes & & \\
\hline Usar uma faca (sem o uso do garfo) & & \\
\hline Usar uma colher & & \\
\hline Usar um martelo & & \\
\hline Usar uma chave de fendas & & \\
\hline Usar uma raquete de ping-pong & & \\
\hline Usar uma faca (com o garfo) & & \\
\hline Usar uma vassoura (mão superior) & & \\
\hline Usar um rodo (mão superior) & & \\
\hline Acender um fósforo & & \\
\hline Abrir um vidro com tampa (mão que segura a tampa) & & \\
\hline Distribuir cartas & & \\
\hline Enfiar a linha na agulha (mão que segura a linha) & & \\
\hline Total & & \\
\hline
\end{tabular}

Quociente de Lateralidade $[(D-E) /(D+E)]$

Dominância Pedal (chutar uma bola)

Dominância Visual Apontando

Acuidade Visual

OE

Visão de Cores

Duração do Sono

Horário Preferido para Acordar

Data da Última Menstruaçăo

Regularidade do Ciclo

Medicamentos em Uso

Hábito de Brincar com Jogos Eletrônicos

Observações 


\section{ANEXO C}

\section{Instruções para a realização do teste}

Você está no Laboratório de Psicofisiologia do Departamento de Fisiologia e Biofísica do ICB USP, sob a responsabilidade do Prof. Luiz Eduardo Ribeiro do Valle. Leia atentamente as instruções abaixo e esclareça eventuais dúvidas com 0 experimentador.

1. Você fará um teste com duração de aproximadamente 30 minutos.

2. Este teste será realizado em uma sala com pouca iluminação. Você permanecerá sentado em frente a um monitor de video, com sua cabeça apoiada em um suporte.

3. Sua tarefa será:

- manter o olhar fixo em um ponto do centro da tela;

- pressionar o mais rapidamente possível a tecla esquerda quando aparecer nesta tela um quadrado dentro de um dos anéis.

- pressionar o mais rapidamente possível a tecla direita quando aparecer um triangulo dentro de um dos anéis.

4. Como a tarefa envolve a identificação de estímulos visuais, para realizá-la você deverá necessariamente estar com seus óculos ou lentes corretivas, caso as use, sob pena de comprometer os resultados do teste.

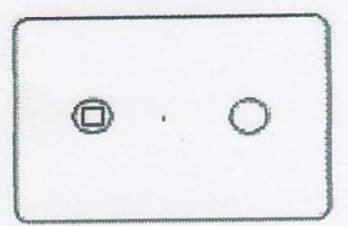

Mẫo esquerda

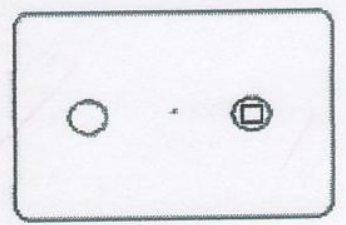

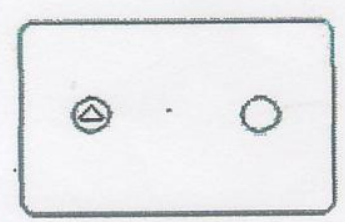

Måo clireitต

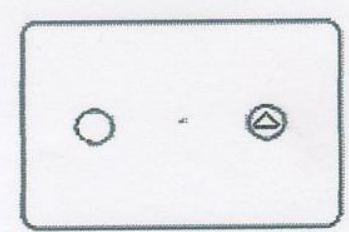




\section{ANEXO D}

\section{Instruções para a realização do teste}

Você está no Laboratório de Psicofisiologia do Departamento de Fisiologia e Biofísica do ICB USP, sob a responsabilidade do Prof. Luiz Eduardo Ribeiro do Valle. Leia atentamente as instruções abaixo e esclareça eventuais dúvidas com o experimentador.

1. Você fará um teste com duração de aproximadamente 30 minutos.

2. Este teste será realizado em uma sala com pouca iluminação. Você permanecerá sentado em frente a um monitor de video, com sua cabeça apoiada em um suporte.

3. Sua tarefa será:

- manter o olhar fixo em um ponto do centro da tela;

- pressionar o mais rapidamente possível a tecla direita quando aparecer nesta tela um quadrado dentro de um dos anéis.

- pressionar o mais rapidamente possível a tecla esquerda quando aparecer um triangulo dentro de um dos anéis.

4. Como a tarefa envolve a identificação de estímulos visuais, para realizá-la você deverá necessariamente estar com seus óculos ou lentes corretivas, caso as use, sob pena de comprometer os resultados do teste.

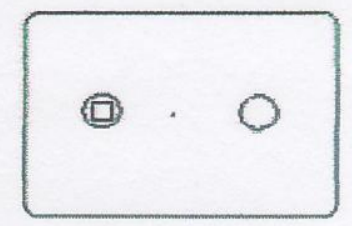

Mâ้o direila

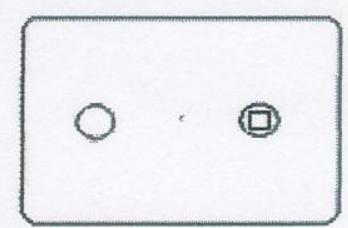

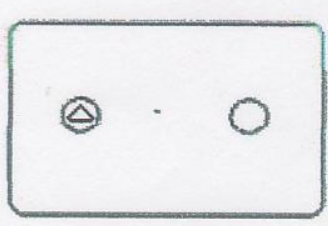

Mẫo esquerda

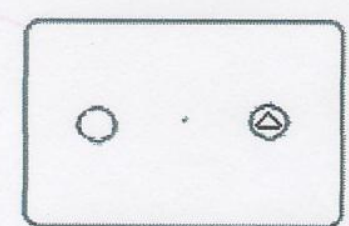


ANEXO E 


\section{Instruções para a realização do teste}

Você está no Laboratório de Psicofisiologia do Departamento de Fisiologia e Biofísica do ICB USP, sob a responsabilidade do Prof. Luiz Eduardo Ribeiro do Valle. Leia atentamente as instruções abaixo e esclareça eventuais dúvidas com 0 experimentador.

1. Você fará um teste com duração de aproximadamente 30 minutos.

2. Este teste será realizado em uma sala com pouca iluminação. Você permanecerá sentado em frente a um monitor de video, com sua cabeça apoiada em um suporte.

3. Sua tarefa será:

- manter o olhar fixo em um ponto do centro da tela;

- pressionar o mais rapidamente possível a tecla direita quando aparecer nesta tela um quadrado.

- pressionar o mais rapidamente possível a tecla esquerda quando aparecer um triângulo.

4. Como a tarefa envolve a identificação de estímulos visuais, para realizá-la você deverá necessariamente estar com seus óculos ou lentes corretivas, caso as use, sob pena de comprometer os resultados do teste.

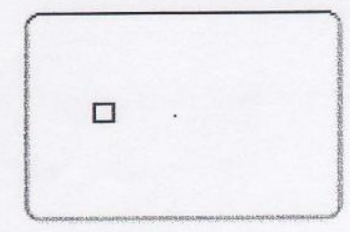

Mẫo direita

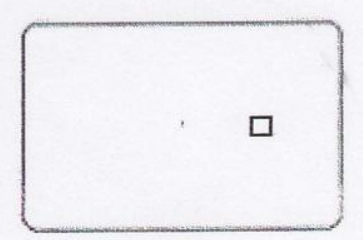

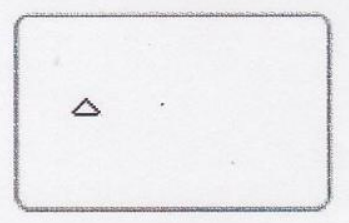

Mẫo esquerda

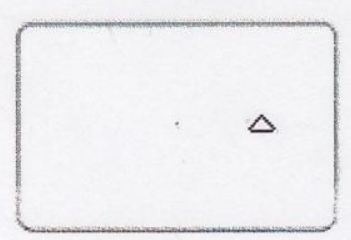


ANEXO F 


\section{Instruções para a realização do teste}

Você está no Laboratório de Psicofisiologia do Departamento de Fisiologia e Biofísica do ICB USP, sob a responsabilidade do Prof. Luiz Eduardo Ribeiro do Valle. Leia atentamente as instruções abaixo e esclareça eventuais dúvidas com o experimentador.

1. Você fará um teste com duração de aproximadamente 30 minutos.

2. Este teste será realizado em uma sala com pouca iluminação. Você permanecerá sentado em frente a um monitor de video, com sua cabeça apoiada em um suporte.

3. Sua tarefa será:

- manter o olhar fixo em um ponto do centro da tela;

- pressionar o mais rapidamente possível a tecla direita quando aparecer nesta tela um quadrado.

- pressionar o mais rapidamente possível a tecla esquerda quando aparecer um triângulo.

4. Como a tarefa envolve a identificação de estímulos visuais, para realizá-la você deverá necessariamente estar com seus óculos ou lentes corretivas, caso as use, sob pena de comprometer os resultados do teste.

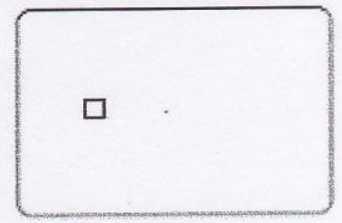

Mẫo direita

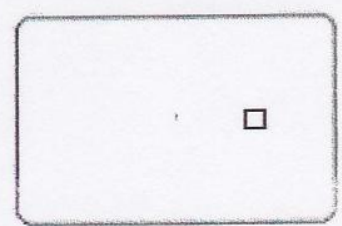

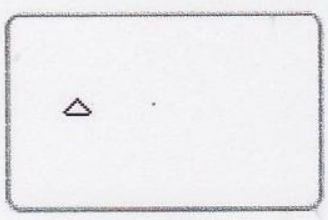

Mẫo esquercla

$\triangle$ 


\section{ANEXO G}

\section{TERMO DE CONSENTIMENTO LIVRE E ESCLARECIDO}

Título do Estudo: "Fatores que influenciam a responsividade a estímulos visuais em seres humanos"

Este docümento tem por finalidade informá-lo sobre os procedimentos de teste que serão utilizados neste estudo bem como obter o seu consentimento expresso em participar do mesmo. A assinatura deste documento não implica em qualquer obrigação da sua parte para com o experimentador.

$\mathrm{Eu}$, domiciliado em

portador do $\mathrm{RG}$

e do CPF ......, abaixo assinado(a), concordo de livre e espontânea vontade em participar como voluntario(a) do estudo sobre os fatores que influes sobre o procedimento e que todas as minhas dúvidas foram devidamente esclarecidas.

Estou ciente de que:

I)

O estudo visa determinar os fatores que influenciam a responsividade do ser humano a estímulos visuais.

II) Farei uma sessão de teste, com duração de aproximadamente 30 minutos. Nesta sessão serão apresentados estímulos visuais aos quais eu deverei responder pressionando uma tecla.

III)

IV)

sessão de teste. Tenho a liberdade de desistir ou de interromper assim o desejar, sem necessidade de qualquer explicação;

V) Concordo que os resultados deste estudo sejam divulgados em publicações científicas, desd que meus dados pessoais não sejam citados;

VI)

Serei informado dos meus resultados ao final deste estudo, caso assim o deseje.

São Paulo,

de

de 201?

Nome e Assinatura:

Telefone:

E-mail:

Testemunha1 :

Nome

RG

Telefone

Testemunha 2 :

Nome

$\mathrm{RG}$

Telefone

Responsável pelo projeto: Patricia Gonçalves 
ANEXO H

Teste de acuidade visual

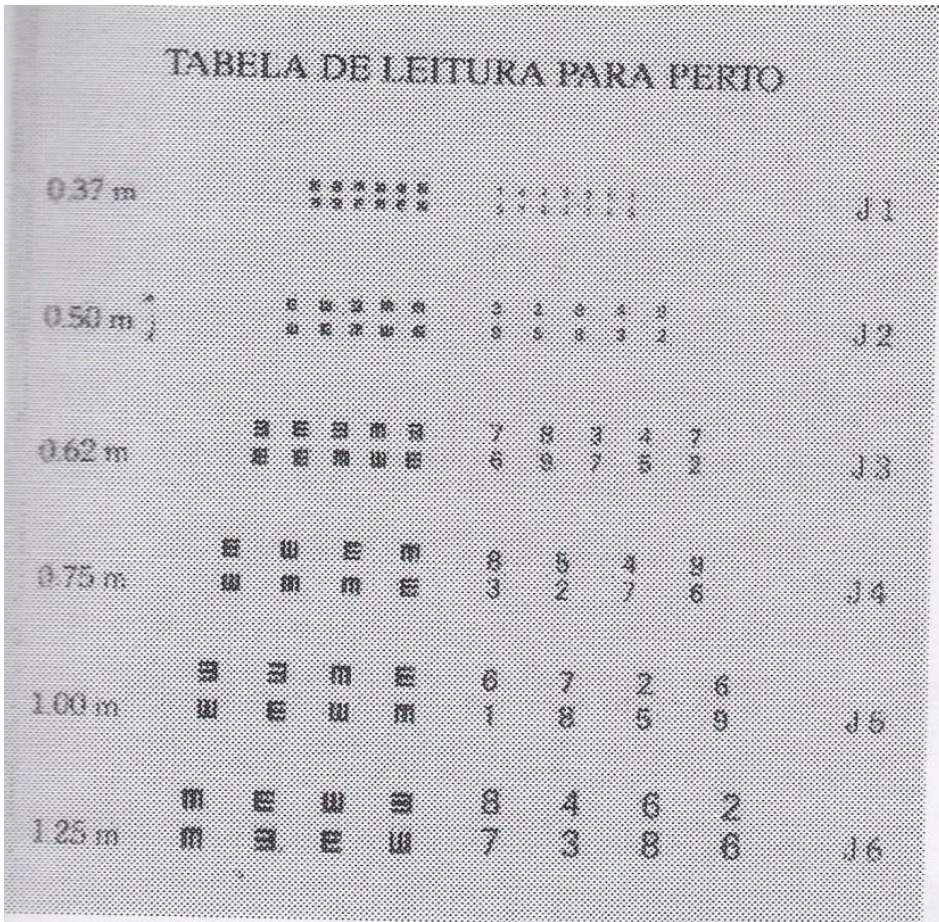

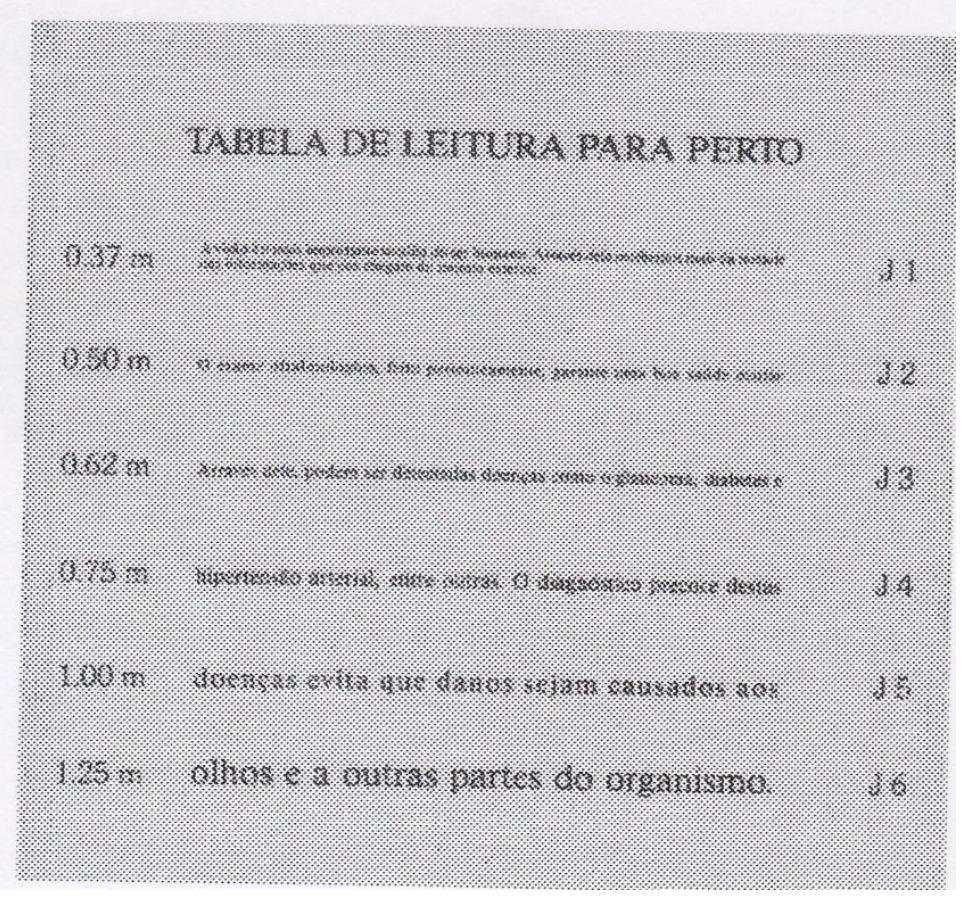


ANEXO I

Teste Ishihara para daltonismo
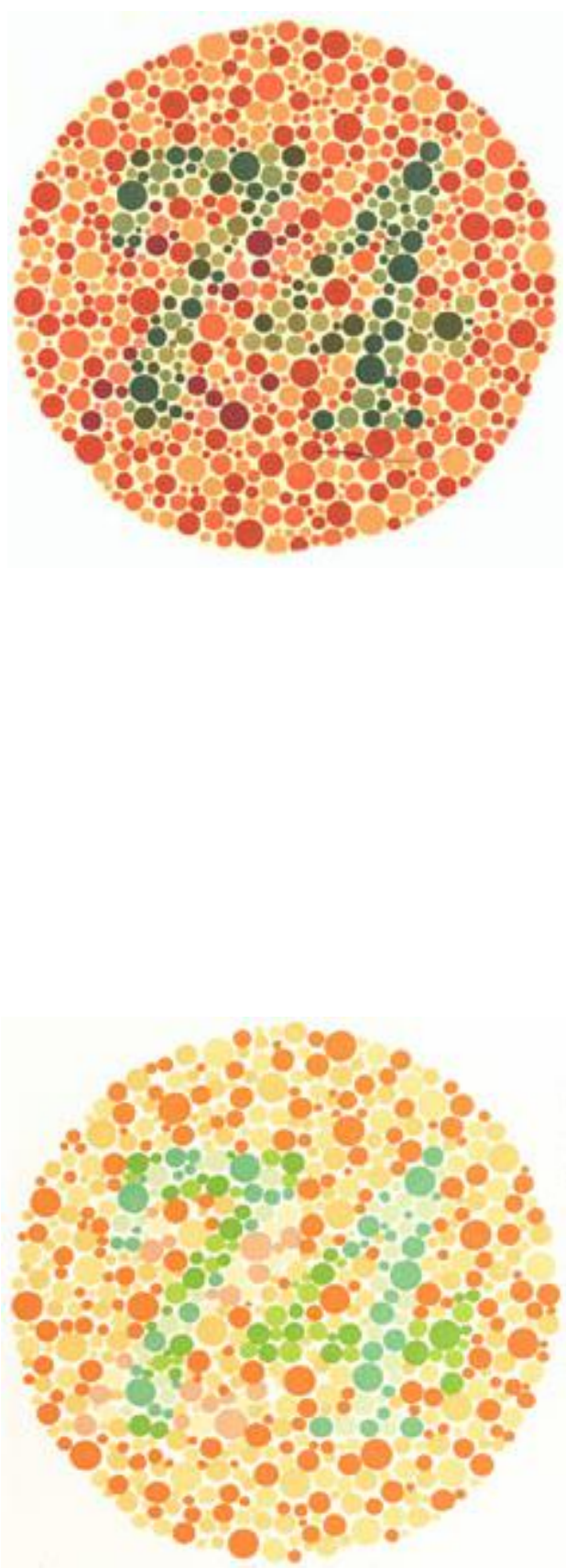


\section{ANEXO $J$}

\section{Tabela de dados do Experimento $1 \mathrm{~A}$}

Tempos de reação (em ms) nas condições de posição mesma $(\mathrm{M})$ e oposta(O).

\begin{tabular}{|c|c|c|}
\hline E1-E2 & $\mathrm{M}$ & $\mathrm{O}$ \\
\hline 3 & 487 & 578 \\
\hline 5 & 397 & 430 \\
12 & 426 & 450 \\
14 & 535 & 570 \\
16 & 380 & 399 \\
18 & 453 & 475 \\
\hline 7 & 427 & 449 \\
\hline 9 & 433 & 452 \\
\hline 11 & 456 & 481 \\
\hline 15 & 465 & 498 \\
\hline 17 & 503 & 537 \\
\hline 19 & 441 & 464 \\
\hline Média & 450 & 482 \\
\hline Epm & 13 & 16 \\
\hline
\end{tabular}




\section{ANEXO K}

Tabela de dados do Experimento $1 \mathrm{~A}$

Tempos de reação (em ms) nas condições de posição mesma $(M)$ e oposta(O), separados por estímulos (quadrado/triângulo) e por congruência da mão de resposta ao lado em que aparece o estímulo alvo.

\begin{tabular}{|c|c|c|c|c|c|c|c|c|}
\cline { 2 - 9 } \multicolumn{1}{c|}{} & \multicolumn{3}{c|}{ Quadrado } & \multicolumn{3}{c|}{ Triângulo } \\
\cline { 2 - 9 } & \multicolumn{2}{c|}{ Congruente } & \multicolumn{2}{c|}{ Incongruente } & \multicolumn{2}{c|}{ Congruente } & \multicolumn{2}{c|}{ Incongruente } \\
\hline E1-E2 & $\mathrm{M}$ & $\mathrm{O}$ & $\mathrm{M}$ & $\mathrm{O}$ & $\mathrm{M}$ & $\mathrm{O}$ & $\mathrm{M}$ & $\mathrm{O}$ \\
\hline 3 & 531 & 633 & 483 & 601 & 463 & 532 & 471 & 547 \\
\hline 5 & 386 & 440 & 383 & 422 & 400 & 431 & 422 & 428 \\
12 & 426 & 453 & 434 & 440 & 407 & 425 & 438 & 483 \\
14 & 538 & 573 & 555 & 582 & 543 & 585 & 505 & 538 \\
16 & 391 & 429 & 379 & 399 & 366 & 383 & 382 & 386 \\
\hline 18 & 429 & 464 & 452 & 467 & 454 & 488 & 478 & 480 \\
\hline 7 & 430 & 442 & 429 & 456 & 420 & 464 & 427 & 433 \\
9 & 437 & 419 & 434 & 483 & 437 & 440 & 424 & 466 \\
11 & 447 & 475 & 449 & 478 & 458 & 474 & 470 & 498 \\
15 & 451 & 528 & 480 & 508 & 465 & 489 & 461 & 465 \\
17 & 516 & 537 & 482 & 513 & 480 & 507 & 533 & 589 \\
\hline 19 & 402 & 461 & 452 & 439 & 443 & 499 & 469 & 455 \\
\hline Média & 449 & 488 & 451 & 482 & 445 & 476 & 457 & 481 \\
\hline Epm & 15 & 19 & 14 & 18 & 13 & 15 & 12 & 16 \\
\hline
\end{tabular}




\section{ANEXO L}

\section{Tabela de dados do Experimento 1B}

Tempos de reação (em ms) nas condições de posição mesma $(M)$ e oposta(O).

\begin{tabular}{|c|c|c|}
\hline E1-E2 & $\mathrm{M}$ & $\mathrm{O}$ \\
\hline 2 & 494 & 549 \\
4 & 452 & 442 \\
6 & 503 & 526 \\
20 & 500 & 529 \\
24 & 558 & 597 \\
26 & 454 & 479 \\
\hline 8 & 529 & 510 \\
10 & 388 & 389 \\
13 & 455 & 460 \\
21 & 454 & 461 \\
23 & 482 & 474 \\
25 & 412 & 434 \\
\hline Média & 473 & 488 \\
\hline Epm & 14 & 16 \\
\hline
\end{tabular}




\section{ANEXO M}

Tabela de dados do Experimento 1B

Tempos de reação (em ms) nas condições de posição mesma $(\mathrm{M})$ e oposta(O), separados por estímulos (quadrado/triângulo) e por congruência da mão de resposta ao lado em que aparece o estímulo alvo.

\begin{tabular}{|c|c|c|c|c|c|c|c|c|}
\cline { 2 - 9 } \multicolumn{1}{c|}{} & \multicolumn{4}{c|}{ Quadrado } & \multicolumn{3}{c|}{ Triângulo } \\
\cline { 2 - 9 } & \multicolumn{2}{c|}{ Congruente } & \multicolumn{2}{c|}{ Incongruente } & \multicolumn{2}{c|}{ Congruente } & \multicolumn{2}{c|}{ Incongruente } \\
\hline E1-E2 & $\mathrm{M}$ & $\mathrm{O}$ & $\mathrm{M}$ & $\mathrm{O}$ & $\mathrm{M}$ & $\mathrm{O}$ & $\mathrm{M}$ & $\mathrm{O}$ \\
\hline 2 & 501 & 580 & 514 & 545 & 484 & 527 & 527 & 543 \\
\hline 4 & 433 & 446 & 467 & 452 & 439 & 445 & 445 & 427 \\
\hline 6 & 484 & 570 & 529 & 542 & 494 & 485 & 485 & 507 \\
20 & 480 & 507 & 505 & 571 & 503 & 517 & 517 & 522 \\
\hline 24 & 547 & 639 & 568 & 618 & 554 & 555 & 555 & 578 \\
\hline 26 & 441 & 497 & 472 & 491 & 444 & 469 & 469 & 461 \\
\hline 8 & 537 & 552 & 536 & 528 & 501 & 476 & 476 & 485 \\
\hline 10 & 379 & 363 & 389 & 415 & 385 & 390 & 390 & 388 \\
\hline 13 & 426 & 470 & 457 & 483 & 441 & 441 & 441 & 447 \\
\hline 21 & 457 & 487 & 476 & 474 & 428 & 435 & 435 & 447 \\
\hline 23 & 458 & 456 & 498 & 524 & 481 & 452 & 452 & 465 \\
\hline 25 & 362 & 440 & 406 & 444 & 439 & 436 & 436 & 416 \\
\hline Média & 459 & 501 & 485 & 507 & 466 & 469 & 469 & 474 \\
\hline Epm & 16 & 22 & 15 & 17 & 13 & 13 & 13 & 16 \\
\hline
\end{tabular}




\section{ANEXO N}

Tabela de dados do Experimento 2

Tempos de reação (em ms) nas condições de posição mesma $(M)$ e oposta(O).

\begin{tabular}{|c|c|c|}
\hline E1-E2 & M & O \\
\hline 27 & 579 & 539 \\
31 & 502 & 567 \\
33 & 627 & 644 \\
\hline 37 & 440 & 420 \\
39 & 431 & 452 \\
40 & 498 & 526 \\
\hline 28 & 401 & 420 \\
\hline 30 & 511 & 553 \\
\hline 32 & 476 & 491 \\
34 & 404 & 422 \\
36 & 543 & 593 \\
\hline 38 & 495 & 521 \\
\hline Média & 492 & 512 \\
Epm & 20 & 21 \\
\hline
\end{tabular}




\section{ANEXO O}

Tabela de dados do Experimento 2

Tempos de reação (em ms) nas condições de posição mesma (M) e oposta(O), separados por estímulos (quadrado/triângulo) e por congruência da mão de resposta ao lado em que aparece o estímulo alvo.

\begin{tabular}{|c|c|c|c|c|c|c|c|c|}
\hline \multicolumn{1}{c|}{} & \multicolumn{3}{c|}{ Quadrado } & \multicolumn{3}{c|}{ Triângulo } \\
\cline { 2 - 9 } & \multicolumn{1}{c|}{ Congruente } & \multicolumn{2}{c|}{ Incongruente } & \multicolumn{2}{c|}{ Congruente } & \multicolumn{2}{c|}{ Incongruente } \\
\hline E1-E2 & $\mathrm{M}$ & $\mathrm{O}$ & $\mathrm{M}$ & $\mathrm{O}$ & $\mathrm{M}$ & $\mathrm{O}$ & $\mathrm{M}$ & $\mathrm{O}$ \\
\hline 27 & 553 & 587 & 670 & 538 & 544 & 516 & 551 & 516 \\
\hline 31 & 479 & 548 & 500 & 615 & 514 & 577 & 516 & 529 \\
33 & 605 & 656 & 580 & 617 & 669 & 653 & 653 & 652 \\
\hline 37 & 406 & 423 & 486 & 423 & 426 & 397 & 443 & 437 \\
\hline 39 & 403 & 424 & 471 & 493 & 413 & 418 & 438 & 473 \\
\hline 40 & 448 & 505 & 475 & 553 & 512 & 483 & 556 & 562 \\
\hline 28 & 344 & 410 & 418 & 425 & 403 & 440 & 439 & 406 \\
\hline 30 & 507 & 555 & 505 & 580 & 539 & 542 & 495 & 535 \\
\hline 32 & 439 & 469 & 469 & 499 & 486 & 490 & 512 & 505 \\
\hline 34 & 384 & 423 & 416 & 444 & 413 & 387 & 403 & 432 \\
\hline 36 & 523 & 591 & 521 & 590 & 579 & 577 & 551 & 614 \\
\hline 38 & 425 & 483 & 536 & 538 & 490 & 512 & 530 & 549 \\
\hline Média & 460 & 506 & 504 & 526 & 499 & 499 & 507 & 517 \\
\hline Epm & 22 & 23 & 20 & 20 & 23 & 23 & 20 & 21 \\
\hline
\end{tabular}




\section{ANEXO P}

Tabela de dados do Experimento 3

Tempos de reação (em ms) nas condições de posição mesma (M), oposta(O) e neutra $(\mathrm{N})$.

\begin{tabular}{|r|c|c|c|}
\hline E1-E2 & $\mathbf{M}$ & $\mathbf{O}$ & $\mathbf{N}$ \\
\hline 42 & 382 & 377 & 337 \\
49 & 440 & 459 & 429 \\
\hline 50 & 404 & 426 & 398 \\
43 & 446 & 443 & 422 \\
\hline 48 & 422 & 423 & 400 \\
\hline 52 & 418 & 455 & 442 \\
\hline 44 & 441 & 452 & 400 \\
\hline 47 & 479 & 472 & 400 \\
\hline 51 & 423 & 446 & 394 \\
\hline 45 & 502 & 495 & 477 \\
\hline 46 & 395 & 428 & 378 \\
\hline 53 & 491 & 519 & 471 \\
\hline Média & 437 & 450 & 412 \\
Epm & 11 & 11 & 11 \\
\hline
\end{tabular}




\section{ANEXO Q}

Tabela de dados do Experimento 3

Tempos de reação (em ms) nas condições de posição mesma (M), oposta(O) Ee neutra, separados por estímulos (quadrado/triângulo) e por congruência da mão de resposta ao lado em que aparece o estímulo alvo.

\begin{tabular}{|c|c|c|c|c|c|c|c|c|c|c|c|c|}
\hline \multirow[b]{3}{*}{ E1-E2 } & \multicolumn{6}{|c|}{ Quadrado } & \multicolumn{6}{|c|}{ Triângulo } \\
\hline & \multicolumn{3}{|c|}{ Congruente } & \multicolumn{3}{|c|}{ Incongruente } & \multicolumn{3}{|c|}{ Congruente } & \multicolumn{3}{|c|}{ Incongruente } \\
\hline & $M$ & 0 & $\mathrm{~N}$ & $M$ & 0 & $\mathrm{~N}$ & $M$ & 0 & $\mathrm{~N}$ & $M$ & 0 & $\mathrm{~N}$ \\
\hline 42 & 401 & 379 & 345 & 389 & 412 & 368 & 339 & 346 & 292 & 400 & 372 & 344 \\
\hline 49 & 420 & 461 & 437 & 468 & 506 & 456 & 434 & 414 & 400 & 439 & 453 & 425 \\
\hline 50 & 375 & 422 & 383 & 427 & 430 & 394 & 400 & 435 & 401 & 413 & 416 & 413 \\
\hline 43 & 400 & 451 & 409 & 453 & 433 & 411 & 459 & 446 & 448 & 471 & 444 & 422 \\
\hline 48 & 404 & 442 & 405 & 428 & 444 & 412 & 432 & 399 & 389 & 426 & 407 & 397 \\
\hline 52 & 404 & 512 & 459 & 407 & 415 & 455 & 419 & 448 & 442 & 441 & 443 & 414 \\
\hline 44 & 366 & 435 & 379 & 478 & 460 & 390 & 457 & 496 & 408 & 463 & 418 & 422 \\
\hline 47 & 457 & 509 & 398 & 458 & 495 & 396 & 532 & 437 & 422 & 471 & 448 & 385 \\
\hline 51 & 449 & 430 & 382 & 413 & 495 & 399 & 416 & 436 & 415 & 413 & 423 & 379 \\
\hline 45 & 508 & 515 & 473 & 481 & 466 & 462 & 528 & 528 & 482 & 492 & 470 & 490 \\
\hline 46 & 355 & 408 & 368 & 378 & 433 & 378 & 427 & 457 & 377 & 421 & 412 & 389 \\
\hline 53 & 449 & 476 & 438 & 468 & 565 & 488 & 508 & 493 & 471 & 538 & 543 & 485 \\
\hline Média & 416 & 453 & 406 & 437 & 463 & 417 & 446 & 444 & 412 & 449 & 437 & 414 \\
\hline Epm & 13 & 12 & 11 & 10 & 13 & 11 & 16 & 14 & 14 & 11 & 12 & 12 \\
\hline
\end{tabular}

